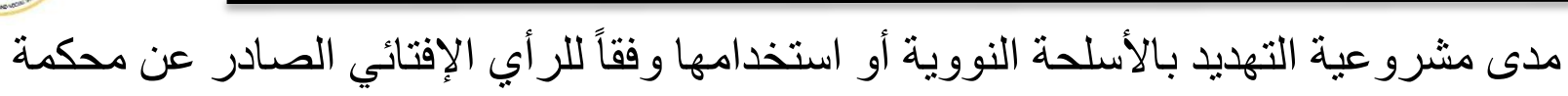
العدل الدولية

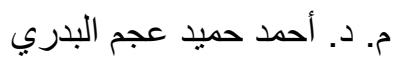

في كلية الإمام الكاظم (عليه السلام) للعلوم الإسلامية الجامعة أقسام واسط الإلري ahmedhameed@alkadhum-col.edu.iq البريد الالكتروني:

الهاتف المحمول : 07812500055

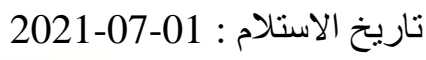

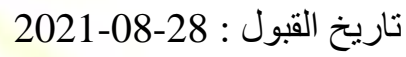

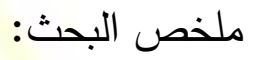

اعتمدت الجمعية العامة للأمم المتحدة في دورتها التاسعة والأربعين قراراً تطلب فيه من محكمة العدل الدولية إصدار فتوى بثأن مدى امكانية التهديد بالأسلحة النووية أو إستخدامها في أي ظرف من الظروف بموجب القانون الدولي، وأثارت إجابة المحكمة على هذه الفتوى عدة إثكاليات، أهمها قرار المحكمة بأنها لا تستطيع الوصول إلى إستتاج حاسم فيما يتعلق بمشروعية أو عدم مشروعية إستخدام دولة ما للأسلحة النووية في ظرف أقصى من ظروف الدفاع عن النفس، حيث يكون بقاؤها معرضاً للخطر، كما ستحاول هذه الدراسة البحث في ولاية المحكمة في الإجابة على الطلب الإفتائي المقدم إليها من الجمعية العامة، وتحليل نصوص القانون الواجب التطبيق على المسألة المستقتى بها، فضلاً عن التطرق لآراء الفقه والآراء الملحقة بالفتوى

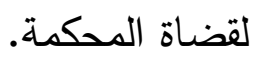
الكلمات المفتاحية: محكمة العدل الدولية/ الإختصاص الإفتائي/ القانون الدولي الإنساني / الأسلحة النووية 
The Legality of the Threat or Use of Nuclear Weapons According to the Advisory

\section{Opinion of the International Court of Justice}

DR. Ahmed Hameed Ajam AL Bdri

Imam Al-Kadhum College (peace be upon him)

University of Islamic Sciences - Wasit branch

Receipt date: 2021-07-01

Date of acceptance: $2021-08-28$

\section{Abstract}

The United Nations General Assembly passed a resolution at its $49^{\text {th }}$ session requesting an advisory opinion from the International Court of Justice on the threat or use of nuclear weapons in any scenario under international law. The court's response to the fatwa created many issues, the most serious of which was the court's finding that it couldn't make a definitive verdict on the legality or illegality of a country's deployment of nuclear weapons in an extreme situation of selfdefense where its survival was at threat. This research will also look into the court's jurisdiction in responding to the General Assembly's fatwa request, look into the relevant legal texts, and look into the jurisprudence and opinions surrounding the fatwa given by the court judges.

keywords: International Court of Justice, Advising Jurisdiction, International Humanitarian Law, Nuclear weapons. 
أصبحت النزاعات المسلحة حالة واقعية لا يمكن تجنبها، بسبب اختلاف المصالح الدولية التي تؤدي إلى التتازع، وما تجّره من معاناة وموت ودمار، حتى صار لازماً على القانون الدولي ان يتصدى لتتظيم النزاع المسلح، ليكون اكثر انسانية، لذا فإن السؤال الذي يطرح دائهاً مفاده: (هل يخضع سلوك الأطراف المشاركة بالنزاع المسلح إلى ضوابط ؟) من هذا الجدلية على وجه التحديد أقدمت الجمعية العامة للأمم المتحدة إلى التقدم بطلب فتوى من محكمة العدل الدولية بثأن مدى مشروعية إستخدام الأسلحة النووية أو التهديد بها وفقاً لقواعد القانون الدولي، وكان السبب الرئيس الذي دفع الجمعية العامة لهذا الإجراء، هو ما أثير من نقاشات قانونية داخل الجمعية العامة حول الموضوع، وخصوصاً بعد ان رفضت محكمة العدل الدولية طلب الفتوى الذي تقدمت به منظمة الصحة العالمية، بعد ان وجدت المحكمة ان الطلب لا ينسجم مع اختصاصات المنظمة. أولاً: أهمية الدراسة

1. تعد مشكلة الأسلحة النووية واحدة من أكبر المشكلات التي تواجه المجتمع الدولي منذ أن وجدت، وذلك لعدم وجود إتفاقية دولية تحظر تلك الأسلحة على وجه التحديد والوضوح، لذا تكتسب هذه الدراسة أهميتها من أهمية الفتوى التي لا تكاد أن تخلو دراسة في القانون الدولي الإنساني من ذكر لإحدى فقراتها. 2. ت تتبث أهمية هذه الدراسة من القيمة القانونية والعملية الكبيرة التي أفرزتها هذه الفتوى، فهي تمثل المرة الأولى التي يتم فيها تحليل قواعد القانون الدولي الإنساني بشيء من التفصيل، حيث تضمنت الدراسة تحليل المحكمة لنصوص هذا القانون، فضلاً عن تحليل دقيق ومفسر للمواد التي لها علاقة بإستخدام القوة في ميثاق الأمم المتحدة، وتحليل نصوص متتاثرة في القانون الدولي لحقوق الإنسان، والقانون الدولي للبيئة، والقانون الدولي للحياد، والإتفاقيات التي تحظر بعض أنواع الأسلحة. 3. تكمن أهمية هذه الدراسة من خلال تطرقها للإختصاص الإفتائي لمحكمة العدل الدولية، حيث ركزت على النظام القانوني لولاية المحكمة في قبول الطلبات الإفتائية التي تقدم إليها، ونطاق سلطتها التقديرية في قبول أو رفض طلب الفتوى، فضلاً عن تضمن هذه الدراسة على المسائل الإجرائية للفتوى التي بحثا فيها بشكل غير مباشر بمناسبة استعراضنا لفقرات الفتوى، إضافة إلى تضمين الدراسة لآراء قضاة المحكمة التي الحقت بالفتوى، سواء أكانت مستقلة أو مؤيدة أو معارضة. 
إن موضوع ((مدى مشروعية التهديد بالأسلحة النووية أو إستخدامها وفقاً للرأي الإفتائي الصادر عن محكمة العدل الدولية)) يثير إثكاليات عديدة أهمها:

1. إلى أي مدى كانت نتيجة الفتوى كافية لحظر إستخدام الأسلحة النووية أو التهديد بها ؟

2. ما هي أوجه القصور التي اعترت تلك الفتوى في مجال تطبيق المضامين التي جاءت بها أحكام القانون الدولي

بثكل عام، وأحكام القانون الدولي الإنساني على وجه الخصوص ؟

3. وقبل هذا وذاك، هل أن السلطة التقديرية الممنوحة للحكمة في قبول أو رفض طلب الفتوى لها محددات أم

أنها لا تخضع لقانون ؟

ثالثاً: منهجية الدراسة

للإجابة عن إثكاليات الدراسة اتبعنا المنهج القانوني التحليلي، والمنهج الوصفي، حيث إعتمنا المنهج القانوني التحليلي

في تحليل فقرات الفتوى، وبالترتيب الذي جاءت فيه في متن الفتوى، كما حاولنا من خلال المنهج الوصفي، وصف النصوص القانونية التي إستشهدت بها المحكمة.

رابعاً: الدراسات السابقة

تناولت المجلة الدولية للصليب الأحمر بعددها الخاص رقم (53) والصادر في شهر شباط عام 1997، هذا القرار من

خلال عدد من البحوث والمقالات لمختصين في القانون الدولي، وقد تمت الاشارة الى بعض ما جاء في هذه البحوث والدراسات في هذا البحث.

رابعاً: هيكلية الدراسة

لقد قسمت هذه الدراسة إلى ثلاثة مباحث وعلى الثكل الآتي:

المبحث الأول: ولاية المحكمة في الإجابة على الطلب الإفتائي المقدم لها من الجمعية العامة. المطلب الأول: حق الجمعية العامة في طلب الفتوى.

المطلب الثاني: السلطة التقديرية للمحمة في قبول طلب الفتوى.

المبحث الثاني: مدى مشروعية الأسلحة النووية وفقاً للإتفاقيات الدولية وميثاق الأمم المتحدة. 
المطلب الأول: مدى مشروعية الأسلحة النووية وفقاً لإتفاقيات حقوق الإنسان والبيئة.

المطلب الثاني: مدى مشروعية الأسلحة النووية وفقاً لميثاق الأمم المتحدة وإتفاقيات الأسلحة. المبحث الثالث: مدى مشروعية الأسلحة النووية في ضوء العرف والحياد والقانون الدولي الإنساني. المطلب الأول: مدى مشروعية الأسلحة النووية وفقاً للقانون العرفي وقانون الحياد. المطلب الثاني: مدى مشروعية الأسلحة النووية وفقاً للقانون الدولي الإنساني. المبحث الأول

ولاية المحكمة في الإجابة على الطلب الإفتائي المقدم لها من الجمعية العامة بحثت المحكمة في بداية الأمر في مدى ولايتها في الإجابة على الطلب الإفتائي الذي تقدت به الجمعية العامة، إذ إستمعت إلى الحجج المؤيدة والحجج الرافضة لولايتها، وقامت بتحليل النصوص ذي الصلة الواردة في ميثاق الأمم المتحدة والنظام الأساس لمحكمة العدل الدولية، وتوصلت بعد ذلك لقرراها، لذا نقم هذا المبحث إلى مطلبين، المطلب الأول في حق الجمعية العامة في طلب الفتوى، أما المطلب الثاني فنبحث فيه في السلطة التقديرية للمحكمة في قبول طلب الفتوى.

المطلب الأول: حق الجمعية العامة في طلب الفتوى خصصنا المطلب الأول من هذا المبحث لدراسة حق الجمعية العامة للأمم المتحدة في طلب الفتوى، حيث سنناقش في الفرع الأول الأساس القانوني الذي يخول الجمعية العامة طلب الفتوى، بينما سيخصص الفرع الثاني للبحث في الخلافات المثارة بثأن صلة المسألة المعروضة بإختصاصات الجمعية العامة، أما الفرع الثالث فخصصناه للبحث في أسباب رفض المحكمة للطلب المقدم إليها من منظمة الصحة العالمية. الفرع الأول الأساس القانوني الذي يخول الجمعية العامة طلب الفتوى اعتمدت الجمعية العامة للأمم المتحدة في دورتها التاسعة والأربعين قرارها المرقم (75/49) في 15/كانون الأول/1994 الذي قررت فيه إستتاداً إلى الفقرة (1) من المادة (96) من ميثاق الأمم المتحدة أن تطلب من محكمة العدل الدولية إصدار فتوها بشأن التساؤل الذي نصه: (هل التهديد بالأسلحة النووية أو إستخدامها في أي ظرف من الظروف يكون مسموحاً به 
بموجب القانون الدولي؟) (قرار الجمعية العامة للأمم المتحدة (A/49/75)،1994، ص1)، وبعد أن تلقى قلم المحكمة أصل القرار وأبلغه للدول التي يجوز لها الحضور أمام المحكمة وتقديم بياناتها الخطية بثأن المسألة المستفتى بها، باشرت المحكمة إجراءات النظر في الطلب، وأول ما التفتت اليه هو الأساس القانوني الذي يخول الجمعية العامة طلب الفتوى.

النص الصريح على إختصاص المحكمة في إجابة الطلب الذي تقدمت به الجمعية العامة ورد في موضعين الأول يتمثل في الفقرة (1) من المادة (96) من ميثاق الأمم المتحدة وهو ذات الأساس الذي أثار إليه قرار الجمعية العامة الذي طلبت بموجبه الفتوى، وتتص هذه الفقرة على أن "لأي من الجمعية العامة أو مجلس الأمن أن يطلب إلى محكمة العدل الدولية إفتاءه في أية مسألة قانونية".

أما الأساس الثاني فيتمثل بنص الفقرة (1) من المادة (65) من النظام الأساس للمحكة والذي ينص على أن "للمحكمة أن تفتي في أية مسألة قانونية بناءً على طلب أي هيئة رخص لها ميثاق الأمم المتحدة بإستفتائها، أو حصل الترخيص لها بذلك طبقاً لأحكام الميثاق المذكور ".

ومما تجدر الإشارة إليه إن رأياً فقيهاً يرى أن هناك أسس قانونية أخرى لطلب الجمعية العامة الفتوى بثأن المسألة المعروضة يتمثل بالمادة (92) من الميثاق، والمادة (1) و (1/36) من النظام الأساس للمحكمة، والتي تقيد جميعها بأن محكمة العدل الدولية هي الأداة القضائية الرئيسة للأمم المتحدة وتشمل ولايتها جميع القضايا المنصوص عليها بالميثاق، ولكن يبدو ان الرأي الفقهي هذا لا يمكن الجزم بصحته، لأنه يستند إلى نصوص قانونية ضمنيه غير صريحة في إثارتها إلى الإختصاص القضائي، بمقابل وجود نصوص قطعية الدلالة. (الثمري، 2015، ص37-38)

وبدأت المحكمة بمناقشة فيما إذا كانت لديها الولاية في نظر طلب الجمعية العامة بشأن المسألة المعروضة، وأول نقاط تحديد تلك الولاية هو الأساس القانوني الذي تتكئ عليه المحكمة حيث أثارت المحكمة في قرارها بشأن المسألة المستفتى بها إلى النصوص أعلاه. (الفتوى،1996، ص10)

فالمحكمة طبقت الأساس القانوني أعلاه، في إطار تحديدها لإختصاصها القانوني أولاً، فهي مسألة لابد منها قبل الدخول في موضوع المستقتى فيه، كما أن هذا الأساس هو تطبيق وتفسير أولي ييرز سلطة المحكمة في إعطاء آراء إفتائية بشأن المسائل القانونية، وهو ما ذهبت إليه المحكمة في جميع آرائها الإفتائية السابقة لهذه الفتوى، ومنها رأيها الإفتائي بشأن شروط الإنضمام إلى عضوية الأمم المتحدة، الصادر عام 1948، وفي رأيها بشأن تفسير معاهدات السلام، الصادر عام 1950، 
وفي رأيها الإفتائي الصادر عام 1973 بثأن مراجعة حكم صادر من المحكمة الإدارية للأمم المتحدة. (الثمري، مصدر

$$
\text { سابق، ص49-31-41) }
$$

وتأسيساً على ما تقدم ذكره يظهر لنا أن محكمة العدل الدولية قد أثارت إلى الأسس القانونية التي تستند إليها في إعطاء

آراءها الإفتائية في كافة الطلبات التي قدمت لها للفتوى، سواء أكانت هذه الإثارة صريحة أو ضمنية، وحتى في حالة رفض الإجابة على تلك الطلبات فإن المحكمة تسوغ ذلك بالإستناد إلى تلك الأسس القانونية، وهو ما نراه إتجاهاً محموداً لها في ذلك الثأن. الفرع الثاني

الخلافات المثارة بشأن صلة المسألة المعروضة بإختصاصات الجمعية العامة بعد أن ذكرت المحكمة الأسس القانونية لولايتها في إجابة طلب الفتوى، إنطلقت لترد على حجج الدول التي دفعت بأن المسألة المعروضة على المحكمة يجب أن تكون داخلة ضمن إختصاصات الجمعية العامة، حيث إنطلقت تلك الدول في هذه الحجة من منطلقين: الأول تقول فيه بأن الجمعية العامة عندما تتقدم بطلب فتوى يكون حالها حال الوكالات والهيأت المتخصصة، ومن ثم يجب أن تكون القضية المستفتى فيها داخلة ضمن إختصاصاتها المرسومة لها بموجب الميثاق، والمنطلق الثاني، يجب أن تكون الجمعية العامة قادرة على إصدار قرار ملزم في القضية التي تستفتي فيها.(الفتوى، مصدر سابق،

ردت المحكمة على تلك الدفوع بثيء من التفصيل، حيث أوضحت بأن هناك فرقاً في الصياغة بين الفقرة (1) والفقرة (2) من المادة (96) من الميثاق، فبينما منحت الفقرة (1) من المادة أعلاه حقاً مطلقاً للجمعية العامة في طلب الفتوى في أي مسألة قانونية، جاءت الفقرة (2) لتعطي لسائر فروع الهيئة والوكالات المتخصصة المرتبطة بها حق طلب الفتوى في المسائل القانونية الداخلة في نطاق اعمالها (ميثاق الأمم المتحدة، 1945، م2/96)، ومن ثم يمكن المساواة بين الجمعية العامة وبين الوكالات والهيئات المتخصصة لوجود فرق واضح في الصياغة، كما رأت المحكة بأنه حتى لو تم مسايرة الدفع أعلاه، فأن الجمعية العامة لها الحق بأن تطلب الفتوى بالمسألة المعروضة، لكونها تملك الإختصاص فيها بموجب المادة (10) والتي تتص على " للجمعية العامة أن تناقش أية مسألة أو أمر يدخل في نطاق هذا الميثاق والمادة (11) التي تتص على "لجمعية العامة أن تتظر في المبادئ العامة للتعاون في حفظ السلم والأمن الدولي، بما في ذلك المبادئ المتعلقة بنزع السلاح وتتظيم 
التسليح..."، والمادة (13) من الميثاق والتي رسمت لها جملة من الإختصاصات التي تجعل من الموضوع المستفتى به داخل ضمن إختصاصاتها عندما نصت على "تنشئ الجمعية العامة دراسات وتثير بتوصيات ....". وينقسم الفقه الدولي بثكل عام إلى إتجاهين بخصوص قدرة الجمعية العامة على طلب الفتوى في أي مسألة قانونية، حيث يذهب الإتجاه الأول إلى أن هناك قيدان أساسيين يردان على حق الجمعية العامة في استثارة المحكمة يتمثلان بقيد الإختصاص الداخلي، وقيد إحترام قواعد توزيع الإختصاص بين أجهزة المنظمة، وأن عبارة "في أية مسألة قانونية" لا يعني إطلاق حق الجمعية العامة بإستشارة المحكمة في القضايا التي تدخل ضمن إختصاص غيرها من الهيئات، وإن القول بخلاف ذلك يعني إعطاء الجمعية العامة حقاً بتجاوز الحدود المرسومة لها بموجب نصوص الميثاق الأخرى. Kelsen, $(1951, \mathrm{P} 137$ أما الإتجاه الثاني فيرى أن الجمعية العامة لها حق طلب الفتوى من المحكمة في "أية مسألة قانونية" دون أي قيود تحد من تلك السلطة إستتاداً للمادة (1/96) من الميثاق، وأن تفسير ذلك وفقاً للمعنى العادي لألفاظ النص يعني تخويل الجمعية العامة حق طلب الفتوى دون أن تمنحها حق التدخل في إختصاص غيرها من الوكالات والهيئات المتخصصة. (شباط وشكري، (205)، ص266 ومن جانبنا نرى أن الإتجاه الثاني هو المرجح، حيث لم يكن هناك ما يبرر للمحمة دخولها في تكييف فيما إذا كانت المسألة المستقتى بها تدخل ضمن صلاحيات الجمعية العامة من عدمه، لأن ذلك يقودنا ضمناً إلى القول بأن المحكمة قد إقتعت بوجه النظر التي تقيد الجمعية العامة بطلب الفتوى في المسائل التي تدخل ضمن إختصاصها، أو إنها أرادت أن تساير وجهات نظر لم تقتنع بها أصلاً، وذلك ما لا يليق بمكانة المحكمة. الفرع الثالث

أسباب رفض المحكمة للطلب المقدم إليها من منظمة الصحة العالمية قدمت منظمة الصحة العالمية بتاريخ 1993/آ1/27 طلباً إلى محكمة العدل الدولية تطلب فيه الفتوى والإجابة على التساؤل الذي نصه " في ضوء الآثار الصحية والبيئية، هل يمثل إستخدام دولة ما للأسلحة النووية في الحرب أو في أي نزاع مسلح آخر خرقاً لإلتزاماتها بموجب القانون الدولي، بما في ذلك دستور منظمة الصحة العالمية؟"، و قدم هذا الطلب بشكل 
سابق لطلب الجمعية العامة الذي نحن بصدد دراسته في هذا البحث، وأن سبب التطرق له في هذه الدراسة كونه قد رد من قبل المحكمة لأسباب تتعلق بموضوع الفرع الأول والفرع الثاني من هذا المطلب.

رأت المحكمة أنه يتوجب تحقق الثروط الثلاثة التي جاءت بها المادة (2/96) من الميثاق لتكون لها ولاية في إجابة الطلب الإفتائي وهذه الشروط هي أن تكون الهيئة أو الوكالة مأذون لها من قبل الجمعية العامة، وأن تكون المسألة المستقتى بها قانونية، وأن تكون المسألة داخلة ضمن نطاق عمل تلك الهيئة أو الوكالة، وقد تم إستيفاء الثرطين الأوليين، غير أن المحكمة وجدت بالنسبة للشرط الثالث أنه على الرغم من أن منظمة الصحة العالمية مأذون لها بموجب دستورها بمعالجة الآثار المترتبة على إستخدام الأسلحة النووية، إلا أن السؤال الذي طرحته المنظمة لا يتصل بآثار إستخدام الأسلحة النووية على الصحة، وإنما بمشروعية إستخدام هذه الأسلحة في ضوء آثارها الصحية والبيئية، وأشارت المحكة إلى أنه مها كانت تلك الآثار فأن إختصاص منظمة الصحة العالمية لا يتوقف على مشروعية الأفعال التي سبيتها، وذلك لأن مسؤولياتها محصورة بمجال الصحة العامة. (موجز الأحكام والفتاوى والأوامر الصادرة عن محكمة العدل الدولية، 1998، ص 108). وعلى أساس ما تقدم قررت المحكمة بأغلبية (11) صوتاً مقابل (3) أصوات إنها غير قادرة الإجابة على طلب الفتوى التي تقدمت بها منظمة الصحة العالمية، وأرفق القضاة الثلاثة المعارضين لرأي المحكمة آراء مخالفة، حيث يقول القاضي (شهاب الدين) في رأيه المخالف: "أن المكمة أخطأت في فهم السؤال، فالمنظمة لا تسأل عما إذا كان إستخدام أحد اعضائها للأسلحة النووية مشروعاً بموجب القانون الدولي بشكل عام، ولكن الأمر الأكثر معقولية أن يفسر سؤالها على أنه إذا كان هذا الأمر يشكل إنتهاكاً لإلتزامات أحد الاعضاء بالقدر الذي يثكل فيه هذا الإنتهاك خرقاً لدستور منظمة الصحة العالمية"، بينما يرى القاضي (ويرامانتري) في رأيه المخالف عدم جدوى وقوع كارثة نووية لتحرك منظمة الصحة العالمية لتقديم خدماتها الطبية، أما القاضي (كورما) فيذهب في رأيه المخالف إلى القول: "أن منظمة الصحة العالمية مسؤولة عن حماية صحة جميع الثعوب، وأن مسؤولياتها تشمل إتخاذ تدابير وقائية، وأن الإجابة على الطلب الإفتائي كان من المكن أن يوفر وقاية من شرور تلك الأسلحة، فضلاً عن السؤال كان فيه طلب الفتوى فيما إذا كانت آثار تلك الأسلحة تشكل خرقاً لدستور المنظمة أو لا تشكل وهو ما لا يمكن إنكار دخوله ضمن نطاق أنشطة الوكالة طالبة الفتوى". (موجز الأحكام ...، مصدر سابق، 
وعلى الرغم من وجاهة الحجج والأسانيد التي إستتد إليها القضاة المخالفون لرأي المحكمة إلا إننا نؤيد ما ذهبت إليه المحكمة من رأي وذلك لأن موقف منظمة الصحة العالمية سوف لن يتغير سواء كان إستخدام الأسلحة النووية مشروعاً أو غير مشروع طالما كانت المنظمة لا تمتلك السلطات التي تسمح لها بتحريم أي نوع من الأسلحة أو الدخول في مجال حفظ السلم والأمن الدوليين أو تتظيم التسليح، حيث تبقى تلك السلطات معقودة بغيرها، فالمنظمة معنية بإتخاذ التدابير الصحية لمعالجة آثار تلك الأسلحة سواء كان إستخدام تلك الأسلحة مبرراً أو غير مبرر من وجهة نظر القانون الدولي. المطلب الثاني: السلطة التقديرية للمحكمة في قبول طلب الفتوى خصصنا المطلب الثاني من هذا المبحث لدراسة السلطة التقديرية للمحكة في قبول طلب الفتوى، حيث سنناقش في الفرع الأول مدى قانونية المسألة المعروضة وتأثير جوانبها السياسية على ولاية المحكمة، بينما خصصنا الفرع الثاني للبحث في مسؤوليات المحكمة بوصفها الأداة القضائية الرئيسية للأمم المتحدة، أما الفرع الثالث فخصصناه للبحث في غموض المسألة المعروضة وإحتمالية تجاوز المحكمة لدورها القضائي. الفرع الأول

مدى قانونية المسألة المعروضة وتأثير جوانبها السياسية على ولاية المحكمة دفعت بعض الدول أن القضية المستقتى بها ذات طابع سياسي، وأن الطلب الذي قدم للمحكمة كان الهدف منه سياسي أكثر مما هو قانوني، وعلى المحكمة أن ترفض إعطاء الفتوى، لأن القضية المعروضة لا تشكل "مسألة قانونية" كما تتطلب ذلك المادة (1/96) من الميثاق ذلك، أجابت المحكمة على هذه الدفع "أنه ليس للطبيعة السياسية للدوافع التي قد يقال أنها حفزت على الطلب، والآثار السياسية التي قد تترتب على الفتوى الصادرة أي صلة بإقامة المحكمة لولايتها لإصدارها تلك الفتوى"، حيث وجدت المحكمة أن القضية المستفتى بها هي مسألة قانونية، وذلك لأن الجمعية العامة قد طلبت من المحكمة أن تصدر فتوى في ما إذا كان إستخدام السلاح النووي يتماشى مع مبادئ القانون الدولي وقواعده ذات الصلة، ولكي تجيب المحكمة يتعين عليها تحديد تلك المبادئ والقواعد وتقسيرها وتطبيقها على القضية المعروضة، وبذلك تعطي المحكمة فتواها إستاداً إلى القانون. (الفتوى،1996، ص12). 
وسبق للمحكمة أن ذكرت في مناسبات كثيرة الحدود الفاصلة بين قانونية المسائل المعروضة وجوانبها السياسية، ففي فتواها الصادرة عام 1975 في قضية الصحراء الغربية بينت المحكمة "أن المسائل المصوغة قانونياً، والتي تطرح مشاكل تتعلق بالقانون الدولي، هي بحكم طبيعتها قابلة لأن يجاب عليها إجابة تستند إلى القانون".(موجز الأحكام...، ص133). كما ترى المحكمة في مناسبة أخرى "كون أن هذه المسألة ذات جوانب سياسية، شأنها شأن الكثير من المسائل التي تطرح في الحياة الدولية ليس كافياً أن يجردها من طابعها القانوني، كما أكدت الحكمة على " أنه في الحالات التي تكون فيها الإعتبارات السياسية بارزة، قد يكون من الضروري بصفة خاصة لمنظمة دولية أن تحصل على فتوى من المحكمة بشأن المبادئ القانونية المنطبقة فيما يتعلق بالموضوع قيد النقاش" (تفسير إتفاق ومصر،1951) 1951) ص17) ويمكن للمحكمة أن تثير تلك المسألة وتناقثها من تلقاء نفسها، حتى دون طلب من الأطراف المعنيين بالأمر، مما يجعل الأمر شبيهاً بالمسائل التي تتعلق بالنظام العام في القانون الداخلي، وهذا ما حدث في فتوى الصحراء الغربية عام 1975 فعلى الرغم من أن المحكمة لاحظت عدم إدعاء أي دولة من الدول بأن المسألة المستفتى بها غير قانونية، إلى أنها وجدت من الضروري التعرض للمسألة بعمق نظراً للشكوك التي أثيرت حول الطابع القانوني للمسألة المعروضة. (Gowlland,1994, P652 P652)

ومن جانبنا لم نجد أن ميثاق الأمم المتحدة أو النظام الأساس للمحكمة أو حتى لائحتها الداخلية يتضمن أي تحديد لمفهوم "المسألة القانونية"، إلى أن المحكمة (كما هو واضح من الآراء التي أشرنها إليها أعلاه) تسعى في أغلب آراءها الإستثارية إلى رسم حدود ذلك المفهوم، فمن غير (قانونية المسألة المعروضة) لا تتعقد للمحكمة ولاية النظر بالطلب، ومهما إمتلكت المحكمة من سلطة تقديرية في الإجابة، فأن تلك السلطة لا تخولها أن تتظر في طلب لا يشكل "مسألة قانونية"، إلى أن المحكمة في ذات الوقت توسعت كثيراً في تحديد هذا المفهوم، إلى أن ذلك كان في محله في جميع فتاواها، بما في ذلك الفتوى المبحوث 
تتص المادة (92) من ميثاق الأمم المتحدة على إن "محكمة العدل الدولية هي الأداة القضائية الرئيسة للأمم المتحدة... "، كما تتص المادة (1) من النظام الأساس لمحكمة العدل الدولية على إن "تكون محكمة العدل الدولية التي ينشئها ميثاق الأمم المتحدة الأداة القضائية الرئيسية للهيئة وتباشر وظائفها وفقاً لأحكام هذا النظام الأساسي". ويتضح لنا من تحليل هذين النصين أن المحكمة تقع عليها مسؤوليات يجب أن لا تتتصل عنها من حيث المبدأ، إلا إذا كان هناك مانعاً قانونياً. دفعت بعض الدول إلى المحكمة أن ترفض طلب الفتوى إستتاداً إلى سلطتها التقديرية، إلا أن المحكمة وجدت أن الفتوى لا تعطى للدول، وإنما للجمعية العامة طالبة الفتوى، وجواب المحكمة وهي إحدى هيئات الأمم المتحدة "يمثل إثتراكها في أنشطة المنظمة، ولا يجب رفضه من حيث المبدأ"، كما وجدت المحكمة "إنها كانت دوماً على بينة من مسؤولياتها بوصفها الأداة القضائية الرئيسة للأمم المتحدة وإنها عندما تتظر في كل طلب تعي أنه لا ينبغي لها من حيث المبدأ أن ترفض إعطاء

$$
\text { الفتوى". (الفتوى، مصدر سابق، ص12). }
$$

هذا ويعد الطلب الذي تقدمت به منظمة الصحة العالمية الذي اشرنا اليه في هذا البحث هو الطلب الوحيد الذي رفضت محكمة العدل الدولية النظر فيه استتادا الى سلطتها التقديرية، أما محكمة العدل الدولية الدائمة، فكان لها رفض في طلب واحد أيضاً، وذلك في قضية (مركز كاريليا الشرقية) والتي كانت لها ملابسات خاصة، من بينها أن المسألة تتعلق بنزاع قائم، وأن أحد الدول الداخلة في النزاع لم تكن طرفاً في النظام الأساسي للمحكمة الدائمة ولا عضواً في عصبة الأمم. وفي رأيه المعارض يقول القاضي (أودا): "أنه كان على المحكمة أن تمتنع عن إصدار الفتوى، حيث لم تكن القضية المستفتى بها ذات صلة بنزاع معروض أو مشكلة ملموسة بحاجة إلى حل قانوني، وأن ذلك الرفض كان يمكن أن يستند إلى جملة مبررات منها (اللياقة القضائية)، و(الإقتصاد القضائي)، حيث يرى (أودا) أنه كان على المحكمة وبداعي (اللياقة القضائية) أن ترفض الطلب لكون أن الإستتتاجات الأولية والغامضة التي وصلت إليها المحكمة لا تثكل إستجابة حقيقية للطلب، ومن ثم يمكن أن تشكل تلك النتيجة ضرراً في مصداقية المحكمة، كما أن(الإقتصاد القضائي) يحتم على المحكمة أن ترفض الإستجابة للطلب، لأن هناك الكثير من القضايا في قانون الدولي للبحار والقانون الدولي الإنساني والقانون الدولي لحقوق الإنسان والقانون الدولي للبيئة تتطلب توضيحاً من المحكمة أيضاً بدون أن تكون هناك حاجة عملية لها، وهذا ما يهدد وظيفة المحكمة الأساسية وهي حل النزاعات ليحولها إلى هيئة إستثارية وربما إلى هيئة تشريعية. (أودا، 1996، ص157). 
ومن جانبنا نرى أن ما توصل إليه القاضي (أودا) من رأي محل نظر ونقاش، حيث يبقى التساؤل الأهم هو متى توصل (أودا) إلى هذا الرأي؟ سيكون الجواب حتماً بعد أن إنتهت المحكمة من تحليل المسألة المعروضة بثكل كامل، لذا فأننا نرى أن المحكمة لم تكن تتوقع أن تصل إلى تلك النتائج الغامضة التي توصلت إليها لترفض الطلب من حيث المبدأ، كما أن توصل المحكمة لهذه النتائج الغامضة ليس من شأنه أن يشكل ضرراً في مصداقية المحكمة كما يرى (أودا) بقدر ما يعرض الحالة الموجودة والتي تجعل من الجهة طالبة الفتوى على بينة مما هو عليه الحال بغية قيامها بواجباتها المرسومة لها بموجب الميثاق. الفرع الثالث غموض المسألة المعروضة واحتمالية تجاوز المحكمة لدورها القضائي دفعت الدول الحائزة للأسلحة النووية أن المسألة المستفتى فيها غامضة ونظرية، وتتعلق بقضايا معقدة، وليس من الثأن الفتوى التي تصدرها محكمة العدل الدولية أن توفر للجمعية العامة أي مساعدة عملية، كما أن هذا النتوى قد تأخر التقدم الذي سبق وأن أحرزته الأمم المتحدة في هذا موضوع، لذا فهي مخالفة لمصلحة الأمم المتحدة، كما أعربت دول أخرى عن مخاوفها من أن تؤدي الطبيعة النظرية للمسألة إلى أن تصدر تصريحات افتراضية أو حدسية تكون خارج وظيفتها القضائية. (البيانات

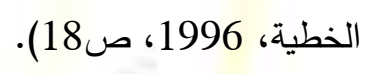
وترى المحكمة أنه من الضروري التمييز بين الثروط التي تتظم الإجراءات المتعقة بالخصومة وبين شروط قبول الفتوى، حيث أن القصد من إعطاء الفتوى هو ليس بالضرورة أن يكون تسوية لنزاع قائم، ومن ثم فإن كون المسألة المستفتى بها لا تتصل بنزاع محدد، يجب أن لا يمنع المحكمة من إعطاء الفتوى المطلوبة. (الفتوى، 1996، ص14) كما وجدت المحكمة إنه ليس من وظائفها أن تقرر فيما إذا كانت الفتوى لازمة أو غير لازمة للجمعية العامة، وأن الجمعية العامة هي من تقرر لنفسها فائدة الفتوى، كما أن المحكمة لا تضع في إعتبارها منشأ الطلب الذي تقدمت به الجمعية العامة، ولا تأريخه السياسي، ولا توزيع الأصوات فيما يتعلق بالقرار المعتد، كما أن الدفع بأن الإجابة على طلب الفتوى يؤخر التقدم الذي أحرزته الامم التتحدة، هي مسألة تقدير، ففي الوقت نفسه دفعت دول أخرى بالقول أن إعطاء الفتوى يمكن أن يعزز من هذا التقدم، وليست ثمة معايير واضحة تستطيع المحكمة على أساسها تفضيل رأي على آخر في هذا الدفع، وأخيراً دفعت بعض الدول بأن المحكمة ستتجاوز دورها القضائي وتعطي لنفسها أهلية سن القوانين، إلا أن المحكمة وجدت أنه لم يطلب منها 
ذلك في الطلب المعروض، كما أن ليس من وظيفتها التشريع، وإنما مهمتها قضائية إفتائية تتلخص بالتثبت من وجود او عدم وجود قواعد ومبادئ قانونية تحكم المسألة المستقتى بها. (موجز الأحكام...، مصدر سابق، ص115). كما دفعت بعض الدول بالقول أن الطبيعة النظرية للمسألة المستفتى بها ربما تدفع المحكمة بإتجاه "تصريحات إفتراضية أو حدسية" تكون خارج نطاق وظيفتها الإفتائية، إلا أن المحكمة وجدت أن إعطاء هذه الفتوى في المسألة المعروضة لا يوجوب عليها " أن تكتب سيناريوهات، وأن تدرس شتى أنواع الأسلحة النووية، وأن تقيم معلومات تكنلوجية واستراتيجية وعلمية هي غاية في التعقيد ومختلف عليها، وإنما ستقوم المحكمة ببساطة في معالجة القضايا بجميع جوانبها وذلك بتطبيق القواعد القانونية ذات الصلة بالحالة". (الفتوى، مصدر سابق، ص14). ويذهب القاضي (غيوم) في رأيه المستقل إلى القول "أن الفتوى تشوبها عيوب كثيرة فهي تعالج بسرعة بالغة مسائل في غاية التعقيد كان ينغي أن تعالج بطريقة أكثر توازناً، وكان في وسع المحكمة في ظل هذه الأحوال أن تتظر في عدم تلبية طلب الفتوى، وكان يمكن لهذا الحل أن يلقي بعض التبرير في ظروف إحالة الطلب". (غيوم، 1996، ص66) وفي نهاية المبحث الخاص بولاية المحكمة في الإجابة على الطلب الإفتائي المقدم لها من الجمعية العامة، نرى أن المحكمة كانت موفقة في قبولها الإجابة على الطلب المقدم لها، وذلك لإنطباق الشروط المذكورة في المادة (1/96) من ميثاق الأمم المتحدة والمادة (1/65) من نظامها الأساس، وأن كل ما قيل من دفوع لإجبار المحكمة على رد الطلب، وعلى الرغم من وجاهة تلك الحجج وقوتها في أحيان كثيرة، إلا أن المحكمة إستطاعت أن ترد عليها بلغة قانونية وعملية، لتقرر في نهاية المطاف الإستجابة لطلب الفتوى، بأغلبية ثلاثة عشر صوت مقابل صوت معارض واحد للقاضي (أودا).

$$
\text { المبحث الثاني }
$$

مدى مشروعية الأسلحة النووية وفقاً للإتفاقيات الدولية

$$
\text { وميثاق الأمم المتحدة }
$$

بعد أن إنتهت المحكمة من تقرير ولايتها في نظر الطلب المقدم إليها من الجمعية العامة، إنتقلت بعدها إلى النظر في القانون واجب التطبيق على الحالة المعروضة أمامها، لتحلل مضامين ذلك القانون بشيء من التقصيل والتحليل، إذ كانت دائماً ما تسع دفوع الدول التي تؤيد عدم مشروعية الأسلحة النووية، ودفوع الدول التي تؤيد المشروعية، لتعطي بعدها رأيها بالموضوع. 
وعلى ضوء ما تقدم قسمنا هذا المبحث على مطلبين، نبحث في المطلب الأول مدى مشروعية الأسلحة النووية وفقاً لإتفاقيات حقوق الأنسان والبيئة، بينما نبحث في المطلب الثاني مدى مشروعية الأسلحة النووية وفقاً لميثاق الأمم المتحدة وإتغاقيات الأسلحة. المطلب الأول

مدى مشروعية الأسلحة النووية وفقاً لإتفاقيات حقوق الأنسان والبيئة قسمنا هذا المطلب إلى ثلاثة فروع حيث نناقش في الفرع الأول العهد الدولي للحقوق المدنية والسياسية، بينما خصصنا الفرع الثاني للبحث في إتفاقية منع جريمة الإبادة الجماعية، أما الفرع الثالث فخصصناه للبحث في القانون الدولي للبيئة. الفرع الأول العهد الدولي للحقوق المدنية والسياسية دفعت بعض الدول المؤيدة لعدم مشروعية الأسلحة النووية، بأن إستخدام الأسلحة النووية ينتهك الحق في الحياة الذي تكفله المادة (1/6) من العهد الدولي للحقوق المدنية والسياسية والتي تتص على أن " الحق في الحياة حق ملازم لكل إنسان، وعلى القانون أن يحمي هذا الحق، ولا يجوز حرمان أحد من حياته تعنفاً"، بينما دفعت الدول المؤيدة لمشروعية الأسلحة النووية بأن العهد الدولي للحقوق المدنية والسياسية لم يتطرق إلى تتظيم الحرب، ولم يذكر فيه تتظيم التسليح، ولم يكن يقصد من العهد أصلاً أن ينظم أو يحكم مشروعية الأسلحة النووية، كما زادت هذه الدول من حدة دفوعها بالقول أن نطاق تطبيق العهد الدولي هو وقت السلم، وأن النزاعات المسلحة يحكمها القانون الدولي الإنساني. (الفتوى، مصدر سابق، ص17) ويعد الحق في الحياة أحد الحقوق الطبيعية التي يجب أن تضمن لكل إنسان، وحماية هذا الحق لا يقتصر على عدم المساس به فقط، بل هو حق يتطلب ضمانة إلتزام بمنع حدوث الإعتداء عليه من جانب الدول الأخرى، ووضع القواعد القانونية الدولية التي تحقق هذه الحماية بصورة فعلية، وتوقع الجزاء على من يعتدي على هذا الحق بأي شكل من الاشكال. (بومدين،

وترى المحكمة أن الحماية القانونية التي يوفرها العهد الدولي للحقوق المدنية والسياسية لا تتوقف أثناء النزاعات المسلحة، سوى بعض الحقوق التي قيدتها المادة (4) من العهد، والتي ليس من ضمنها حق الإنسان بالحياة، لذا فأن هذا الحق لا يتوقف إعماله أثناء النزاعات المسلحة، لكن يبقى تقرير مدى تحقق "الحرمان التعسفي للحياة" المشار له المادة (1/6) من العهد الدولي 
رهناً بقواعد القانون الدولي الإنساني، الذي يمكن أن يقرر لنا أن هذا الحرمان كان تعسفياً أو غير تعسفي. (الفتوى، مصدر

$$
\text { سابق، ص18) }
$$

ويرى الكاتب (مانفريد مور) أن المحكة لم تتطرق إلى الملاحظة التي أبدتها لجنة حقوق الإنسان والمكلفة بدراسة تطبيق العهد الدولي للحقوق المدنية والسياسية على المسألة المستفتى بها، ففي هذا الموضع كانت اللجنة قد وصفت إستخدام الأسلحة النوية بأنها أكبر تهديد لحق الانسان في الحياة، وطالبت هذه اللجنة بحظر تلك الأسلحة وإعتبارها جريمة ضد الإنسانية، إذ كان من واجب المحكمة أن تتظر على نحو أكثر تفصيلًا بين إثكالية الأسلحة النووية وحق الانسان في الحياة، في هذا المجال فأن الآثار متوازية، لأن إستخدام الأسلحة النووية يمس حق الإنسان في الحياة ويمس المبادئ العامة للقانون الدولي الإنساني على السواء، وعلى أساس ذلك يتطابق القانون الدولي الإنساني، والقانون الدولي لحقوق الإنسان. (مور، 1997،

ومن جانبنا نرى أن حق الإنسان في الحياة هو حق أصيل، وأن كل ما ينهك هذا الحق أو يمس به يعتبر غير مسموح به إستتاداً إلى مجموعة كبيرة من النصوص الواردة في مختلف الصكوك الدولية والأعراف والمبادئ العامة بما ذلك المادة (1/6) من العهد الدولي للحقوق المدنية والسياسية، وعلى أساس ذلك كان على المحكمة أن تتوسع في تحليل تلك النصوص قبل أن تحيل المسألة إلى القانون الدولي الإنساني ليحكم فيها، لأن رأيها هذا من شأنه أن يصلنا إلى نتيجة مفادها أن تطبيق قواعد القانون الدولي لحقوق الإنسان في أوقات النزاع المسلح يظل معقوداً على ما تقره قواعد القانون الدولي الإنساني في نظام يثبه إلى حد كبير نظام الإحالة في القانون الدولي الخاص، مما يشكل إجحافاً كبيراً بقواعد القانون الدولي لحقوق الإنسان بشكل عام، وبحق الإنسان بالحياة على وجه الخصوص. الفرع الثاني إتفاقية منع جريمة الإبادة الجماعية دفعت بعض الدول المؤيدة لعدم مشروعية الأسلحة النووية، بأن إستخدام تلك الأسلحة يكون محظوراً إستتاداً إلى أحكام إتقاقية منع جريمة الإبادة الجماعية لعام 1948، حيث تثير المادة الثانية من تلك الإتفاقية على "تعني الإبادة الجماعية أياً من الأفعال التالية، المرتكبة على قصد التدمير الكلي أو الجزئي لجماعة قومية أو أثنية أو عنصرية أو دينية، بصفتها هذه: أ: قتل أعضاء من الجماعة. ب: إلحاق أذى جسدي أو روحي خطير بأعضاء من الجماعة. ج: إخضاع الجماعة، عمداً، لظروف 
معيشية يراد بها تدميرها المادي كلياً أو جزئياً. د: فرض تدابير تستهدف الحؤول دون إنجاب الأطفال داخل الجماعة. هـ: نقل أطفال من الجماعة، عنوة، إلى جماعة أخرى."، إذ ترى تلك الدول بأنه من شأن إستخدام الأسلحة النووية أن يؤدي بحياة عدد هائل وكبير من البشر، ومن الممكن أن يكون من بين الضحايا أشخاص من مجموعة قومية أو أثنية أو عنصرية أو دينية، ويمكن الإستدلال على وجود نية لإهلاك تلك المجموعة من حقيقة أن مستخدم الأسلحة النووية قد أغفل حسبان الآثار المعروفة جيداً لإستخدام تلك الأسلحة. (موجز الأحكام...، مصدر سابق، ص116) وترى المحكمة بأن إتفاقية منع جريمة الإبادة الجماعية والمعاقبة عليها لعام 1948 يمكن أن تكون أساساً قانونياً لحظر إستخدام الأسلحة النووية، إذا كان إستخدام تلك الأسلحة بنية القضاء على مجموعة محددة بالذات، لذا فأن المحكمة ترى أن هذا الفرض لا يمكن التحقق منه إلا بعد دراسة ملابسات كل قضية ممكن أن تحدث لمعرفة فيما إذا كانت أو لم تكن هناك نية مبيته إتجاه مجموعة بعينها. (الفتوى، مصدر سابق، ص19) وتعد جريمة الإبادة الجماعية إحدى أخطر الجرائم الدولية، لأنها تمثل إعتداء على مصلحة جوهرية يسعى القانون الدولي إلى حمايتها، إلا وهي حماية الإنسان وحق بقاءه، إذ يتجسد جوهر هذه الجريمة في إنكار حق البقاء لـجموعات بشرية معينة، وهي بذلك تتطوي على مجافاة للضمير العام، فضلاً عن مجافاتها للمبادئ العامة للقانون الدولي، كما أن أفعال الإبادة الجماعية التي تصيب جماعة بعينها ولمجرد كونهم مجموعة أشخاص تربط بينهم روابط معينة (دينية أو عرقية أو قومية) تمثل أقصى درجات الوحشية التي تتطوي عليها نفسيات مرتكبي هذه الجريمة، وهذه الأفعال تعد بلا شك من الجرائم ضد الإنسانية، بل تعد أخطر صور الأفعال التي تقع بها تلك الجرائم. (حمودي، 2015، ص124) وتأتي هذه الجريمة على رأس الجرائم الداخلة في إختصاص المحكمة الجنائية الدولية، وعرفتها المادة السادسة من نظام روما الأساس على "إنها أي فعل يرتكب بقصد إهلاك جماعة قومية أو أثنية أو عرقية أو دينية بصفتها هذه إهلاكاً كلياً أو جزئياًا". ونرى إن المحكمة كانت على صواب بإجابتها على هذا الدفع، إذ أن التعريف الوارد في المادة (2) من إتفاقية منع جريمة الإبادة الجماعية لعام 1948، قد بين على وجه لا يقبل التأويل بأن القصد الذي تستهدفه هذه الجريمة هو القضاء على مجموعة محددة بذاتها، وهذا يعني أن إستخدام الأسلحة النووية الذي يمكن أن يوجه لدولة ما، ويدمرها، وهو بذات هذا التذمير يقضي على مجموعة معينة من المجموعات التي تسكن هذه الدولة، لا يمكن أن تتطبق عليه أحكام هذه الإتفاقية طالما لم يكن 
القصد من وراء إرتكاب هذه الجريمة هو القضاء على مجموعة بعينها، لذا فأن رأي المحكمة وأن كان محبطاً للدول التي لا تؤيد إستخدام السلاح النووي، لكننا نرى فيه ليس أكثر من تقسيراً للقانون الموجود.

الفرع الثالث

القانون الدولي للبيئة

دفعت الدول التي لا تؤيد إستخدام الأسلحة النووية، بأن إستخدام تلك الأسلحة يمكن أن يثكل إنتهاك لأحكام القانون

الدولي للبيئة، ومن ثم فهو محظوراً تبعاً لذلك، وقد أشارت تلك الدول إلى صكوك دولية محددة من بينها المادة (3/35) من البروتوكول الإضافي الأول لعام 1977 الملحق بإتفاقيات جنيف الأربعة لعام1949، التي تحظر إستخدام وسائل وأساليب يقصد بها أن تلحق بالبيئة الطبيعية أضرار واسعة الإنتشار وطويلة الأمد وجسيمة، وإتفاقية حظر إستخدام تقنيات التغيير في البيئة لأغراض عسكرية أو أي أغراض عدائية أخرى لعام 1977، فضلاً عن الإثارة إلى فقرات محددة من إعلان ستوكهولم

لعام 1977، وإعلان ريو لعام 1992. (موجز الاحكام....، مصدر سابق، ص116)

بينما أعربت الدول التي تؤيد إستخدام الأسلحة النووية عن شكوكها في الطبيعة الملزمة لقواعد القانون الدولي للبيئة، وفي

إطار إتفاقية حظر إستخدام تقنيات التغيير في البيئة لأغراض عسكرية أو أي أغراض عدائية أخرى وجدت تلك الدول أنها لم يكن يقصد منها حظر إستخدام الأسلحة النووية، كما أدعت تلك الدول أنها غير ملزمة بأحكام البروتوكول الإضافي الأول لعام 1977، أو أن بعض تلك الدول كان متحفظاً على المادة (3/35) من هذا البروتكول عند التوقيع عليه، بينما دفعت دول أخرى بأن أحكام القانون الدولي للبيئة تتطبق في وقت السلم، حيث لم تتطرق تلك الأحكام إلى الأسلحة النووية ولم تورد بين نصوصها ذكراً للحرب بصفة عامة، أو الحرب النووية بثكل خاص، وأنه ما يزعزع الثقة بحكم القانون أن تفسر تلك الاحكام بالشكل الذي تحظر معه إستخدام الأسلحة النووية. (الفتوى، مصدر سابق، ص28).

وإستهلت المحكمة ردودها على الدفوع المقدمة من الطرفين بالقول أن "البيئة عرضة للتهديد يومياً، وأن إستخدام الأسلحة

النووية يشكل كارثة بيئية"، وأكدت كذلك إن "البيئة ليست فكرة مجردة، وإنما تمثل المعيشة، ونوعية الحياة، وصحة الكائنات البشرية ذاتها، بما في ذلك الأجيال القادمة". (موجز الاحكام ....، مصدر سابق، ص116). 
كما ترى المحكمة أن المشكلة ليست ما إذا كانت أحكام القانون الدولي للبيئة تنطبق أو لا تنطبق أثناء النزاعات المسلحة، ولكن فيما إذا كانت الإلتزامات المتولدة عن هذه الأحكام قصد بها حظر إستخدام الأسلحة النووية أم لم يقصد، كما أن هذه الأحكام لا يمكن لها أن تحرم دولة ما من حقها في الدفاع عن النفس، مع الأخذ بالإعتبارات البيئية لتحديد ما هو ضروري ومتتاسب في سعي الدول لتحقيق أهدافها العسكرية، وهكذا تصل المحكمة إلى القول بأن القانون الدولي للبيئة وأن لم يحظر تحديداً إستخدام الأسلحة النووية، إلا أنه يشير إلى عوامل بيئية هامة ينبغي أخذها بالحسبان عند تطبيق قواعد القانون الدولي الإنساني بشكل عام ومبدئي الضرورة والتناسب على وجه الخصوص. (البدري،2015، ص99-90) ومن المهم بدرجة كبيرة أنّ المحكمة أقرت وجود القانون الدولي للبيئة (العرفي والإتفاقي)، كما أكدت المحكمة الطابع العرفي لإتفاقيات جنيف الأربع لعام 1949، وفيما يتعلق بالبروتوكول الإضافي الأول لعام 1977، ذكرت المحكمة إنّ "جميع الدول ملتزمة بهذه القواعد"، والتي كانت عند إعتمادها مجرد تعبير عن القانون العرفي الذي كان قائماً قبلها. (الفتوى، مصدر

$$
\text { سابق، ص20). }
$$

وليس من الواضح تماماً إذا كانت هذه الإثارة إلى "التتاسب والتمييز" تثير إلى القيود الأكثر عمومية الكامنة في سياق قانون الدفاع عن النف، أو إلى مبدأ تتاسب الضرر الجانبي في إطار القانون الدولي الإنساني، فإذا كان الأمر يتعلق بالقانون الدولي الإنساني، فإن ذلك يعني في الواقع بأن " البيئة " هي "ثيء مدني"، وأنه يتعين التخلي عن الهجوم على هدف عسكري إذا كان تأثيره في البيئة يتجاوز قيمة الهدف العسكري، وهناك الكثير مما يدفع إلى تأييد هذا الرأي، ليس في صيغة فتوى المحكمة فحسب، ولكن أيضاً في سياق النصوص التي صدرت مؤخراً عن القانون الدولي الإنساني والقانون الدولي للبيئة، وهذا يعني أنه ليس من السهل القول بأن قاعدة التتاسب لا تنتهك على أساس واحد هو أن الهجمات وقعت في أماكن قليلة السكان أو غير مأهولة، وقد أشارت المحكمة إلى قرار الجمعية العامة رقم (37/47) في 25 تشرين الثاني 1992 بشأن حماية البيئة في أوقات النزاع المسلح، إذ ذكرت " إنها تؤكد وجهة النظر العامة التي تقول بأن تدمير البيئة الذي لا تبره الضرورة العسكرية

$$
\text { والذي يتم بصورة متعددة يتعارض بوضوح مع القانون الدولي القائم". (بيك، 1997، ص50) }
$$

وعلى أساس ما تقدم فأننا نؤيد ما ذهبت إليه المحكمة من آراء وهي بصدد تحليلها لمدى إنطباق قواعد القانون الدولي للبيئة على إستخدام الأسلحة النووية، حيث وجدت المحكمة أن القانون الذي يجب أن تستند عليه لإجابة الجمعية العامة على 
سؤالها هو القانون الذي ينظم اللجوء المشروع للقوة والقانون الذي ينظم اللجوء الفعلي للقوة، وهي تثير بذلك إلى ميثاق الأمم المتحدة والقانون الدولي الإنساني.

$$
\text { المطلب الثاني }
$$

مدى مشروعية الأسلحة النووية وفقاً لميثاق الأمم المتحدة وإتفاقيات الأسلحة سيتم تقسيم هذا المطلب إلى ثلاثة فروع حيث سنناقش في الفرع الأول أحكام الميثاق المتصلة بالتهديد بالقوة أو إستعمالها، بينما سيخصص الفرع الثاني للبحث التتويه بإمتلاك الأسلحة النووية، أما الفرع الثالث فسيخص للبحث في إتفاقيات الأسلحة. الفرع الأول أحكام الميثاق المتصلة بالتهديد بالقوة أو إستعمالها قبل دخول المحكمة في تحليل نصوص ميثاق الأمم المتحدة التي ترسم شروط وآليات إستخدام القوة بثكلها المشروع، وصفت المحكمة الأسلحة النووية بأنها " أجهزة متفجرة تنجم طاقاتها عن إلتحام الذرة أو إنشطارها... فالقوة التدميرية للأسلحة النووية لا يمكن إحتوائها في حيز أو زمن، إذ تكمن فيها إمكانية تدمير الحضارة بكاملها، والنظم الإيكولوجي للكرة الأرضية برمتها... ويتعين على المحكمة (عند إصدارها تلك الفتوى) أن تضع في نظر الإعتبار الخواص الفريدة للأسلحة النووية لاسيما القوة التدميرية وقدرتها على إيقاع الضرر بالأجيال القادمة". (الفتوى، مصدر سابق، ص21-22). أما بشأن النصوص الواردة في الميثاق التي تتظم إستعمال القوة أو التهديد بها، فهي كل من المادة (4/2) والتي تتص على "يمتتع أعضاء الهيئة جميعاً في علاقاتهم الدولية عن التهديد بإستعمال القوة أو إستخدامها ضد سلامة الأراضي أو الاستقلال السياسي لأي دولة أو على أي وجه آخر لا يتفق ومقاصد الأمم المتحدة"، إلا أن هذه النص يجب أن ينظر إليه في ضوء نصوص الميثاق الأخرى ذات الصلة بإستخدام القوة ففي المادة (51) يعترف الميثاق بالحق الطبيعي للدول بحق الدفاع عن النفس، حيث تص هذه المادة على أن " ليس في هذا الميثاق ما يضعف أو ينتقص الحق الطبيعي للدول، فرادى أو جماعات، في الدفاع عن أنفسهم إذا اعتدت قوة مسلحة على أحد أعضاء "الأمم المتحدة" ...، والتدابير التي إتخذها الأعضاء إستعمالًا لحق الدفاع عن النفس تبلغ إلى المجلس فوراً، ...". كما تتضمن المادة (42) من الميثاق وجهاً آخر من وجه الإستعمال المشروع للقوة مناطة بمجلس الأمن الذي له الحق بموجبها بإتخاذ تدابير عسكرية وفقاً للفصل السابع من الميثاق. 
وتحلل المحكمة نصوص الميثاق المتصلة بإستخدام القوة ومدى إنطباقها على إستخدام الأسلحة النووية بقولها أن الميثاق لا يحظر ولا يبيح صراحة إستخدام أي أسلحة بعينها ومنها الأسلحة النووية، وأن السلاح المحرم بموجب قواعد القانون الدولي (الإتفاقية أو العرفية) لا يصبح مشروعاً لكونه يستخدم لغرض مشروع بموجب الميثاق، كما أن إخضاع حق الدفاع عن النفس لشرطي الضرورة والتتاسب هو قاعدة من قواعد القانون الدولي العرفي التي لا يمكن تجاهلها. (الفتوى، مصدر سابق، ص 23)

وتثير المحكمة في رأي سابق لها بأن "هنالك قاعدة مفادها أن الدفاع عن النفس لا يسوغ إلا تدابير تكون متتاسبة وضرورية مع الهجوم المسلح، وهي قاعدة راسخة تماماً في القانون العرفي، وهذا الشرط ينطبق بالقدر نفسه على المادة (51) من الميثاق أياً كانت وسائل القوة المستخدمة". (قضية الأنثطة العسكرية ...، 1986، ص94) لتصل المحكمة بعد هذا التحليل إلى أي خطير مفاده "أن مبدأ التتاسب ربما لا يستبعد بحد ذاته إستخدام الأسلحة النووية للدفاع عن النفس في كافة الظروف، إلا أنه في الوقت نفسه ينبغي لإستعمال القوة التي تكون متتاسبة بموجب قانون الدفاع عن النفس، لكي يكون مشروعاً، أن يفي بمتطلبات القانون الساري وقت النزاع المسلح، وهي التي تتكون بصفة خاصة من مبادئ القانون الدولي الإنساني وقواعده". (الفتوى، مصدر سابق، ص23). وإقترحت بعض الدول التي لا تؤيد إستخدام الأسلحة النووية في مرافعاتها الخطية والثفهية أن يجري في حال إستخدام الأسلحة النووية تقييم شرط التناسب في ضوء المزيد من العوامل الأخرى، حيث ترى هذه الدول أن طبيعة الأسلحة النووية وخصائصها الفريدة، وإحتمالية تصاعد تبادل إستخدام هذه الأسلحة، يعنيان حصول دمار، وأن ما يترتب على ذلك من آثار ينفي إمكانية الإمتثال لشرط التتاسب، ولا ترى المحكمة ضرورة العمل على تحديد تلك المخاطر ، ويكفي للمحمة أن تلاحظ أن الأسلحة النووية ومخاطرها وآثارها، يجب أن تأخذ بنظر الإعتبار من قبل الدول التي تستخدم حقها بالدفاع عن النفس وفقاً لمقتضيات مبدأ التتاسب. (موجز الأحكام ...، مصدر سابق، ص116). ويذهب القاضي (غيوم) في رأيه المستقل الملحق بالفتوى إلى تأييد ما ذهبت إليه المحكمة بقوله إنه: "لا يمكن لميثاق الأمم المتحدة، ولا لأي قاعدة عرفية أو إتفاقية المساس بالحق الطبيعي في الدفاع عن النفس الذي تثير له المادة (51) من الميثاق، وعلى أساس ذلك فأن القانون الدولي لا يحرم الدولة من حق اللجوء إلى إستخدام الأسلحة النووية، إذا كان هذا اللجوء هو الوسيلة الوحيدة لضمان بقائها". (غيوم ، مصدر سابق، ص63) 
ونذهب نحن بذات الإتجاه الذي ذهب إليه القاضي (فيراري برافو) في رأيه الملحق المستقل بالفتوى، وهو ينتقد ما توصلت

إليه المحكمة في هذا الخصوص عندما يقول: " أن المحكمة ساعدت برأيها هذا على توسيع الفجوة بين المادة (4/2) والمادة (51) من الميثاق". (موجز الأحكام ...، مصدر سابق، ص120) حيث نرى أن سؤال الجمعية العامة المطروح على المحكمة لم يكن يتطلب الدخول إلى تفاصيل تخص قدرة الدولة بالدفاع عن نفسها بإستخدامها الأسلحة النووية، وكان على المحكمة أن لا تغوص في ذلك. الفرع الثاني التتويـه بإمتلاك الأسلحة النووية دفعت بعض الدول التي لا تؤيد إستخدام الأسلحة النووية، بأن حيازة تلك الأسلحة (حتى بدون إستخدامها) يعد تهديد بإستعمال القوة، وهي تبعاً لذلك محظورة إستتاداً للمادة (4/2) من الميثاق والتي تتص على أن "يمتتع أعضاء الهيئة جميعاً في علاقاتهم الدولية عن التهديد بإستعمال القوة ...."، وترى المحكمة أن حيازة تلك الأسلحة يمكن أن يشكل بالفعل إستعداداً لإستخدامها، و(سياسة الردع) التي تسعى تلك الدول من خلالها إلى إفشال أي عدوان يوجه لها تستوجب مصداقيتها لإستخدام السلاح النووي أو على الأقل بأنها تنكر به بجدية، إذ تتجه بعض الدول أحياناً إلى التتويه بأنها تمتلك سلاح نووي بغية تقليل خطر أي هجوم عسكري قد تتعرض له، وترى المحكمة أنه يتوجب لتقرير فيما إذا كان هذا التتويه يشكل أو لا يشكل (تهديداً) وفقاً للمادة (4/2) من الميثاق، فالأمر يتوقف على عوامل مختلفة، فإذا كان إستعمال القوة المزمع القيام به غير مشروع، فأن التهديد بها هو غير مشروع أيضاً، فمن غير المشروع أن تقوم دولة بالتهديد لضم دولة إليها أو لتجبرها لتتبع سياسة إقتصادية

$$
\text { معينة. (الفتوى، مصدر سابق، ص24-25). }
$$

حيث يتضح لنا من خلال تحليل المحكمة لهذا الدفع بأنها تصل إلى نتيجة مفادها أن مصطلحي (إستخدام القوة) و(التهديد بها) المشار لهما في المادة (4/2) من الميثاق هما مصطلحان متلازمان، فمتى ما كان (إستخدام القوة) محظوراً كان (التهديد بها) محظوراً أيضاً والعكس صحيح، وهذا يعني أنه لكي يكون التتويه أو التهديد بإستخدام السلاح النووي مشروعاً ينبغي أن يكون ذلك الإستخدام متققأً مع أحكام ميثاق الأمم المتحدة. 
وفي رأيه المعارض الملحق بالفتوى يقول القاضي (ويرمانتري) "إن مبدأ عدم إستخدام التهديد راسخ كمبدأ عدم إستعمال القوة، ولم يخضع في صياغاته العديدة لأي إستثاءات، ومن ثم إذا كان الردع شكلاً من أشكال التهديد فلابد من أن يكون

$$
\text { مشمولاً بالتحريم الوارد على إستخدام التهديد". (ويرمانتري، 1996، ص310). }
$$

أما القاضي (شي جيويونغ) في رأيه المستقل الملحق بالفتوى فإنه ينتقد ما توصلت إليه المحكمة بخصوص عدم إمكانيتها تجاهل الممارسة المدعوة (سياسة الردع)، حيث ينتقدها بالقول" إن الردع النووي أداة سياسية تستخدمها دول معينة حائزة لأسلحة نووية في علاقاتها مع الدول الأخرى، ويزعم إنها تمنع نشوب نزاع مسلح كبير أو حرب وتحافظ على السلم والأمن بين الدول، ولاثك إن في هذه الممارسة من جانب دول معينة حائزة للأسلحة النووية تقع ضمن إطار السياسة الدولية لا في إطار القانون، وليس لها أي أهمية قانونية .... ولن تخلط المحكمة بذلك بين السياسة والقانون فحسب، بل ستخذ موقفاً قانونياً إزاء سياسة الردع، وبذلك تزج نفسها في السياسة الدولية، وهذا لا يتفق مع وظيفتها القضائية". (شي جيويونغ، 1996، ص56). ومن جانبنا نرى أن المحكمة كانت على صواب بإستتتاجها الذي توصلت إليه والذي كان مفاده "إذا كان إستعمال القوة المزمع القيام به غير مشروع، فأن التهديد بها هو غير مشروع أيضاً"، مما يعني أن التهديد الذي تقوم به دولة ما في سبيل الدفاع عن نفها إذا ما تعرضت لخطر من دولة أخرى يكون مشروعاً بشكل بديهي طالما أن إستخدامها لحقها في رد هذا الخطر مسموحاً به وفق الميثاق، أما عدم تجاهلها (سياسة الردع) فنرى أنه كان في غير محله، فإستتاد المحكمة إلى أدوات سياسية في تحليلها (مسألة قانونية) يفقدها هيبتها القضائية.

الفرع الثالث إتفاقيات الأسلحة

بعد أن إنتهت المحكمة من تحليل نصوص ميثاق الأمم المتحدة المتصلة بإستخدام القوة أو التهديد بها ومدى إنطباقها على المسألة المستقتى بها، تحولت المحكمة لبيان رأيها في الدفوع المقدمة بصدد إنطباق إتفاقيات الأسلحة على المسألة المعروضة على المحكمة. دفعت بعض الدول بأن الاسلحة النووية يجب أن تعامل على نحو ما تعامل به الأسلحة السامة، وهي بذلك تكون محظورة تبعاً لذلك، حيث أوردت تلك الدول ذكر بعض الصكوك الدولية في دفوعها، ومنها إعلان لاهاي الثاني لعام 1899 
الذي يحظر إستخدام القذائف التي يهدف منها بث الغازات الخانقة والضارة، والمادة (23/أ) من النظام المتعلق بقوانين الحرب البريه وأعرافها المرفق بإتفاقية لاهاي الرابعة لعام 1907، والتي بموجبها يمنع بصفة خاصة إستعمال السم او الأسلحة السامة، وكذلك بروتوكول جنيف لعام 1925 الذي يمنع الإستعمال الحربي للغازات الخانقة أو السامة أو ما شابهها من سوائل أو مواد او وسائل. (موجز الأحكام ...، مصدر سابق، ص117) وترى المحكمة أن الصكوك المشار لها وما تحمله من مصطلحات مثل مصطلح (ما شابهها) قد فهم حسب ممارسة الدول بالمعنى العادي لهذه المصطلحات، على إعتبار أن نطاق تطبيقها يثمل الأسلحة التي يكون اثرها الرئيس أو حتى الحصري هو التسميم أو الخنق، وتَعتَبر المحكمة أن هذه الممارسة واضحة، إذ لم تعتبر الأطراف الداخلة في هذه الصكوك إنها تشير الى الأسلحة النووية وتأسيساً على ما تقدم فأن المحكمة ترى أن إستخدام الأسلحة النووية لا يمكن أن يعد محظوراً إستتاداً إلى الصكوك الدولية التي تحرم الأسلحة السامة. كما وترى المحكمة أنها لا تجد أي حظر محدد للأسلحة النووية في الصكوك الدولية الخاصة بعدم مشروعية أسلحة الدمار الثامل، إذ ترى المحكمة أنه قد تم التفاوض على الصكوك عدم مشروعية أسلحة الدمار الثامل وإعتمادها بسياقها الخاص ولأسبابها الخاصة، حيث لم يكن في تفكير الدول الداخلة في تلك الصكوك أن تخضع الأسلحة النووية للحظر وفقاً لتلك الصكوك. (الفتوى، مصدر سابق، ص27) وتلاحظ المحكمة أن المعاهدات الدولية التي لا تتعلق سوى بالحصول على الأسلحة النووية، وصنعتها، وحيازتها، ونشرها، وتجربتها، دون أن تتطرق بصورة محددة إلى التهديد بها أو إستخدامها، تدل على قلق كبير ومتزايد لدى المجتمع الدولي من هذه الأسلحة، ومن هذا تستتج المحكمة إلى أن هذه المعاهدات يمكن أن ينظر إليها على أنها أيذان بمستقبل يحظر فيه السلاح النووي حظراً عاماً شاملاً، أما بخصوص معاهدتي تلاتيلولكو وراروتونغا وبروتكولاتهما، وإعلانات تمديد معاهدة عدم إنتشار الأسلحة النووية إلى أجل غير مسهى، فتبين للمكمة من خلال هذه المعاهدات: (موجز الاحكام ...، مصدر سابق، ص117). 1. أن عدداً من الدول قد تعهدت بعدم إستخدام الاسلحة النووية في مناطق معينة (أمريكا اللاتينية، جنوب المحيط الهادئ) أو ضد دول معينة أخرى (الدول غير الحائزة للأسلحة النووية) التي هي أطراف في معاهدة عدم إنشار الأسلحة النووية. 2. أن الدول الحائزة للأسلحة النووية وحتى ضمن هذا الإطار قد إحتفظت بالحق في إستخدام الأسلحة النووية في ظروف 
3. أن هذه التحفظات لم تعترض عليها الأطراف في معاهدتي تلاتيلولكو وراروتونغا وبروتكولاتهما، ولم يعترض عليها مجلس

الأمن.

ويرى الكاتب (ماك كورماك) وهو أستاذ القانون الدولي الإنساني بكلية القانون / جامعة ملبورن في استراليا وعميد اللجنة

الدولية للصليب الأحمر الاسترالية، أن المحكمة قد أخفقت في تحليل معاهدة عدم إنتشار الأسلحة النووية، حيث أغفلت الفتوى

الإثارة إلى (183) دولة هي الآن أطراف في المعاهدة، إذ تعهدت هذه الدول بتطبيق حظر شامل على إنتاج وتخزين وإختبار

وإستخدام الأسلحة النووية، لذلك فأن الإدعاء بعدم وجود قانون يحكم إستخدام الأسلحة النووية أو التهديد بها هو إدعاء تمييزي، من حيث أنه لا ينطبق إلا على الدول الخمس الحائزة للأسلحة النووية الأطراف في معاهدة عدم الإنتشار، (وهي بالصدفة الأعضاء الدائمة في مجلس الأمن)، وكذلك على الدول التي رفضت الإنضمام إلى معاهدة عدم الإنتشار، أما لجميع الدول الأخرى فأن قانون الأسلحة النووية واضح بجلاء وهو إستخدام الأسلحة النووية أو التهديد بها محظوراً على وجه التحديد

$$
\text { والصراحة. (كورماك، 1997، ص181-81). }
$$

ونحن من جانبنا نؤيد رأي الكاتب (ماك كورماك) في ما توصل إليه بشأن تحليل معاهدة عدم إنتشار الأسلحة النووية، حيث حاولت المحكمة من خلال رأيها بهذه النقطة بالتقيد الحرفي لتحليل النصوص الإتفاقية من خلال تفسيرها الضيق لتلك النصوص، أما ما توصلت إليه المحكمة من آراء بشأن تحليل نصوص صكوك تحريم الأسلحة السامة وأسلحة الدمار الثامل فنرى أنها كانت موفقة في تحليل تلك النصوص، وإن عدم توسعها في نطاق أو مدى تلك النصوص كان في محله.

$$
\text { المبحث الثالث مدى مشروعية الأسلحة النووية في ضوء العرف والحياد }
$$

نتناول في المبحث الثالث من هذا البحث ما توصلت إليه محكمة العدل الدولية عند تحليلها لمدى إنطباق القانون الدولي العرفي والقانون الدولي للحياد والقانون الدولي الإنساني على إستخدام الأسلحة النووية أو التهديد بإستعمالها. وعلى ضوء ما تقدم يقسم هذا المبحث على مطلبين، نبحث في المطلب الأول مدى مشروعية الأسلحة النووية وفقاً للقانون العرفي وقانون الحياد، بينما نبحث في المطلب الثاني مدى مشروعية الأسلحة النووية وفقاً للقانون الدولي الإنساني. 
مدى مشروعية الأسلحة النووية وفقاً للقانون العرفي وقانون الحياد سيتم تقسيم هذا المطلب إلى ثلاثة فروع حيث نناقش في الفرع الأول مدى وجود قاعدة عرفية تحظر الإستخدام، بينما يخصص الفرع الثاني للبحث في مدى قدرة قرارات الجمعية العامة على تكوين قاعدة عرفية، أما الفرع الثالث فخصصناه للبحث في قانون الحياد. الفرع الأول مدى وجود قاعدة عرفية تحظر الإستخدام يعد العرف الدولي سبباً مهماً من أسباب نشوء قواعد القانون الدولي، اذ إن أغلب قواعد هذا القانون ذات الصفة الدولية قد نثأت وإستقرت في المحيط الدولي عن طريق العرف وتحت تأثيره، وحتى القواعد الواردة في الإتفاقيات الإنسانية كثيراً ما تكون تعبيراً أو صياغة لها إستقر عليه العرف قبل إبرامها. (البيطار، 2008، ص1198)، وتتثأ القاعدة العرفية الدولية إذا توافر ركنان أساسيان لها، هما: الركن المادي الذي يتحقق من ممارسات الدول لقاعدة معينة يتكرر إستعمالها، والركن المعنوي الذي يقصد به الثعور بالإلتزام بالقاعدة بوصفها قاعدة قانونية ملزمة، ولا يشترط في العرف الدولي ان يكون تصرفاً إيجابياً، حيث من الممكن أن يكون تصرفاً سلبياً مؤداه الإمتتاع عن القيام بعمل. (الفتلاوي، 2009، ص23). وفي إطار المسألة المستفتى بها دفعت بعض الدول المؤيدة لعدم مشروعية الأسلحة النووية بوجود قاعدة عرفية تحظر إستخدام تلك الأسلحة، وهي تشير بذلك إلى ممارسة ثابتة هي عدم إستعمال الدول للأسلحة النووية منذ عام 1945، وترى هذه الدول أن هذه الممارسة هي "تعبير عن إعتقاد لدى الدول التي تحوز تلك الأسلحة بإلزامية الممارسة"، أما الدول الأخرى الحائزة للأسلحة النووية فأنها دحضت وجود مثل هذه القاعدة العرفية، وإستثهدت دعماً لحجتها بسياسة الردع، إذ ترى هذه الدول بأنها كانت ولازلت تحتفظ بحقها في الدفاع عن النفس ضد أي هجوم مسلح يهدد وجودها، وهي ترى أن عدم إستخدامها للأسلحة النووية منذ عام 1945 لا يعود سببه إلى وجود قاعدة عرفية كما إدعت بعض الدول، ولكنه ومن حسن الحظ لم تأتِ ظروف

$$
\text { تستدعي إستخدام تلك الاسلحة. (الفتوى، مصدر سابق، ص32). }
$$

أما المحكمة فقد كان لها رأي سابق في نشوء القاعدة العرفية عندما قررت بأنه "يجب البحث عنها بصورة أولية في الممارسة الفعلية للدول وإعتقادها بإلزامية الممارسة". (قضية الرصيف القاري...،1985، ص29) وتلاحظ المحكمة أن أعضاء 
المجتمع الدولي منقسمون إنقساماً كبيراً حول مسألة ما إذا كان عدم اللجوء الى الأسلحة النووية خلال الخمسين سنة السابقة للفتوى يشكل إعتقاداً بإلزامية الممارسة، لذا فأن المحكمة "لا تعتبر نفها قادرة على أن تحكم بوجود قاعدة عرفية قد نشأت بهذا

$$
\text { الصدد". (موجز الأحكام ...، مصدر سابق، ص117) }
$$

ويرى نائب رئيس المحكمة القاضي (شويبل) في رأي المخالف بأن المحكمة لم تكن موفقة في إستتاجها هذا، إذ أن تلك

الدول قامت وعلى مدى الخمسين سنة الماضية بصنع ونشر الأسلحة النووية، وأن خطر إمكانية الإستخدام كان ممكناً، ولكن لم تقم تلك الدول بالإستخدام، وإن ممارسة عدم الإستخدام لم تكن ممارسة دولة معارضة وحيدة، بل هي ممارسة الدول الحائزة جميعاً، وهم أعضاء مجلس الأمن الدائمين، بتأييد من عدد كبير من دول العالم الكبيرة، والتي تشكل معاً معظم القوة في العالم، وعدداً كبيراً من سكانه ويضيف " كيف لنا أن نحكم بأن خمسين سنة من ممارسة الدول لا تحظر، ومن ثم تؤيد مشروعية التهديد بالأسلحة النووية أو إستخدامها في ظروف معينة". (شويبل، 1996، ص89) أما نحن فنرى أن ما توصلت إليه المحكمة كان دقيقاً، إذ لا يمكن للقاعدة العرفية أن تتشأ ويتم الإحتجاج بها مالم تستوفي ركنيها المادي والمعنوي، وإذا كان الكلام عن توافر الركن المادي ممكناً في الحالة المعروضة، فأن الركن المعنوي لا يمكن أن نقر بوجوده، فالشعور بالإلتزام بالقاعدة بوصفها قاعدة قانونية ملزمة لم يتوافر ما دامت أن الدول الحائزة للأسلحة النووية (وهي المعنية بإنشاء تلك القاعدة) لم تقر بوجود مثل هذا الإعتقاد، حيث بينت تلك الدول بأن عدم الإستخدام كان ناشئاً عن عدم الحاجة، ولذلك لا يمكننا أن نبني قاعدة على إعتقاد غير متوافر في ذهن من يجب أن يصدر عنه. الفرع الثاني

مدى قدرة قرارات الجمعية العامة على تكوين قاعدة عرفية على الرغم من إن المادة (38) من النظام الأساسي لمحكمة العدل الدولية قد نصت على مصادر القانون الدولي بشكل محدد، إلا إنّ التطور الذي رافق هذا القانون وظهور فروع جديدة له، دعا البعض إلى القول بأن هناك مصادر جديدة له تتمثل في القرارات الصادرة عن المنظمات الدولية، والتي كان لها دوراً مهماً في بلورة قواعد دولية ونشوه أعراف مستقرة في مجال النزاعات المسلحة. (البدري، مصدر سابق، ص100)

وفي إطار القضية المستفتى بها دفعت بعض الدول التي تؤيد عدم مشروعية الأسلحة النووية أو التهديد بها إلى القول بأن مجموعة القرارات الكبيرة والمهمة الصادرة عن الجمعية العامة للأمم المتحدة يمكن أن تدل على وجود قاعدة عرفية تحظر 
اللجوء إلى تلك الأسلحة، حيث قامت الجمعية العامة وأبتداءً من قرارها الرقم (1653) الصادر عام 1961 بإصدارها بشكل دوري ومتكرر قرارات تحظر الأسلحة النووية، وسارعت الدول التي تؤيد مشروعية الأسلحة النووية بالرد على هذا الدفع بما مفاده أن قرارات الجمعية العامة بحد ذاتها غير ملزمة، ولا تثكل أي تفسير لقاعدة عرفية ولا يمكنها كذلك أن تنشأ قاعدة عرفية، فضلاً عن أن هذه القرارات لم تلق موافقة من الدول الحائزة للأسلحة النووية عند التصويت عليها، بل ولم تلق موافقة

$$
\text { عدد كبير من الدول الأخرى أيضاً. (الفتوى، مصدر سابق، ص32). }
$$

وردت الدول المؤيدة لعدم مشروعية الأسلحة النووية على تلك الحجج بالقول إن تلك القرارات لم تدع إلى إيجاد قواعد

جديدة، بالقدر الذي أكدت فيه على التذكير بقواعد القانون الدولي العرفي المتعلق بحظر وسائل وأساليب الحرب التي تتجاوز ما هو مسمح به أثناء القتال، وهذا يعني أن تلك القرارات لم تفعل أكثر من أن شملت حظر الاسلحة النووية بنطاق تلك القواعد العرفية، فهي على حد قول تلك الدول "لم تزد عن كونها الأداة أو الغلاف التي تحتوي قواعد عرفية دولية موجودة من قبل".

$$
\text { (موجز الأحكام .... مصدر سابق، ص117). }
$$

وترى المحكمة بأن قرارات الجمعية العامة وأن كانت غير ملزمة، إلا أنها يمكن أن يكون لها في بعض الأحيان قيمة معيارية، فبإمكانها توفير دليل لله أهمية في إثبات وجود قاعدة عرفية، أو نشوء إعتقاد بإلزامية ممارسة، ومن الممكن أن تدل مجموعة قرارات على النشوء التدريجي لذلك الإعتقاد اللازم لإقامة القاعدة الجديدة، وقرارات الجمعية العامة إذا نظر إليها كمجموعة واحدة فأنها تتضمن ما مفاده أن إستخدام الأسلحة النووية يثكل إنتهاكاً مباشراً لميثاق الأمم المتحدة، وإن هذا الإستخدام يجب أن يحظر، وهكذا فأن تلك القرارات وأن كانت دليلاً واضحاً على قلق عميق إزاء مشكلة الأسلحة النووية، إلا إنها لازالت قاصرة عن إثبات وجود قاعدة بإلزامية الممارسة بشأن عدم مشروعية إستخدام الأسلحة النووية أو التهديد بها.

$$
\text { (الفتوى، مصدر سابق، ص33-34). }
$$

وتتميز القرارات التي تصدر من الجمعية العامة بأهمية كبيرة، كونها صادرة من جهاز يضم في عضويته كل دول العالم تقريباً، وعلى الرغم من الطبيعة القانونية غير الملزمة لهذه القرارات، إذا ما علمنا أن الجمعية العامة للأمم المتحدة تصدر توصيات حسب المادة (10) من ميثاقها، وكذلك فأن بعض قراراتها تصدر بأغلبية بسيطة أو توافق الآراء، إلا أنها تتمتع بإحترام كبير بإعتبارها صادرة عن توافق إرادة الدول الأعضاء في الجماعة الدولية، إذ يرى البعض - ونؤيدهم في ذلك- " إن 
هذه القرارات أصبحت تثكل مصدراً جديداً للقانون الدولي لم يتوقعه النظام الأساسي لمحكمة العدل الدولية، أو أنها في الأقل

تشكل وجهة نظر جديدة لخلق قواعد قانونية دولية". (Kiss, 1991,P109 )

ومن جانبنا نرى أن المحكمة ضيقت نطاق قرارات الجمعية العامة بشأن المسألة المعروضة إلى الحد الذي أفرغ تلك

القرارات من محتواها، إذ ان (القيمة المعيارية) التي أثارت لها المحكمة بشأن تلك القرارات كان يمكن أن يجعل منها ذات

فاعلية قانونية أكبر مما توصلت أليه المحكمة من رأي.

الفرع الثالث

قانون الحياد

يعرّف الحياد الدولي على أنه إلتزام تقطعه الدولة على نفسها بعدم التدخل في الثؤون الدولية، إذا كان هذا التدخل يفضي

إلى إستخدام القوة المسلحة، ويهذف الحياد على الحفاظ على مركز قانوني محدد يفرده القانون الدولي للدول التي تمارس هذا

الحق، وبذلك تتمتع هذه الدول بمجموعة من الحقوق، ويلقى على عاتقها مجموعة من الواجبات ناشئة عن هذا الإلتزام. أما

الدول المحايدة فهي الصفة القانونية لدولة ما، تمتنع بموجبها عن المشاركة في أي حرب أو نزاع بين الدول الأخرى، وتلتزم مسافة واحدة من جميع الأطراف المتتازعة مع ضرورة إعتراف الدول الأخرى بحيادية هذه الدولة وعدم المساس بها أثناء

$$
\text { النزاعات المسلحة. (العيسمي،2011، ص11). }
$$

وفي القضية المعروضة على المحكة دفعت الدول المؤيدة لعدم مشروعية الأسلحة النووية، بأن إستخدام تلك الأسلحة

يمكن أن ينتهك قانون الحياد، من خلال تقديمها فرض مفاده أن إستخدام تلك الأسلحة بطبيعة الحال لا يعترف بحدود دولة ما، فإذا ما تم الإستخدام من الدولة (أ) بقصد أن يكون هذا الإستخدام موجه نحو الدولة (ب) فأن الدولة المحايدة (ج) التي تقع بجوار الدولة (ب) ستكون ضحية من ضحايا هذا الإستخدام للأسلحة النووية بكل تأكيد، وهذا يضر بقانون الحياد الذي يجب على جميع الدول إحترامه أثثاء النزاعات المسلحة. أما المحكمة فقد وجدت أن "مبدأ الحياد بمعناه التقليدي كان يهدف إلى منع القوات المتحاربة من الإغارة على إقليم محايد أو القيام بهجمات على أشخاص وسفن تابعة للدول المحايدة، وهكذا فأن إقليم الدولة المحايدة حرام، وأن للدول المحايدة مصلحة متساوية في أن يحترم المتحاربون حقوقها"، وبعدها خلصت المحكمة إلى رأيها بإنطباق قانون الحياد على المسألة 
المستقتى بها بتقريرها أن مبدأ الحياد أيا كان مضمونه هو ذو طابع أساسي مثله مثل القانون الدولي الإنساني، ينطبق رهناً

$$
\text { بأحكام ميثاق الأمم المتحدة المتصلة بإستخدام القوة. (الفتوى، مصدر سابق، ص39) }
$$

أما القاضي (ويرمانتري) فيذهب في رأيه المعارض الملحق بالفتوى إلى القول بأنه عندما تستخدم الأسلحة النووية، فأن أثرها الطبيعي والمتوقع والمتمثل في إلحاق ضرر يتعذر جبره بالأطراف الثالثة غير المحاربة إعتبار ضروري يلزم أخذه بالحسبان في تقرير السماح بإستخدام هذا السلاح، فالأمر لا يقتصر على دولة غير محاربة واحدة قد يلحقها ضرر لا يمكن تداركه، وإنما يتعلق الأمر بالمجتمع الدولي برمته. (ويرمانتري، مصدر سابق، ص283) أما نحن من جانبنا فنرى أن قانون الحياد بإمكانه أن يثكل أساساً قانونياً لحظر الأسلحة النووية، وحتى الحجة التي قدمتها الدول الحائزة للأسلحة النووية والمتضمنة عدم توافر النية عند إستخدام تلك الأسلحة بإلحاق أضرار بدول أخرى غير الدولة المستهدفة، هو دفع مردود وذلك كون أن إستخدام السلاح النووي هو أمر متعدد، والإضرار بالمحايدين هو نتيجة طبيعية ومتوقعة، ومن ثم فإنها نتيجة حتمية لا يمكن لدولة تجاهلها أو توقع نتيجة غيرها، وعلى أساس ما تقدم نرى أن المحكمة لم تكن حازمة عندما بينت رأيها بشأن مدى إنطباق قواعد قانون الحياد على المسألة المستقتى بها. المطلب الثاني

$$
\text { مدى مشروعية الأسلحة النووية وفقاً للقانون الدولي الإنساني }
$$

سنناقش في هذا المطلب مدى مشروعية الأسلحة النووية وفقاً للقانون الدولي الإنساني، حيث سنستعرض في الفرع الأول مبادئ القانون الدولي الإنساني، وفي الفرع الثاني سنناقش مدى إنطباق القانون الدولي الإنساني على الأسلحة النووية، أما الفرع الثالث سنبحث فيه مدى مشروعية الأسلحة النووية في أقصى ظروف الدفاع عن النفس، وهو الجزء الأكثر تعقيداً في الفتوى.

$$
\begin{aligned}
& \text { الفرع الأول } \\
& \text { مبادئ القانون الدولي الإنساني }
\end{aligned}
$$

تمثل المبادئ العامة للقانون الدولي الإنساني الحد الأدنى من النزعة الإنسانية التي تتطبق على كل زمان، وفي كل مكان، وتحت أي ظروف، والتي تحظى بقبول جميع الدول حتى دون أن تكون هذه الدول أطراف في الإتفاقيات التي تضمنت على 
وفي القضية المستقتى بها، حاولت المحكمة إعطاء تعريفات عامة توضح كيفية تكوين ونثأة القانون الدولي الإنساني، حيث بينت أن هذا القانون يتكون من (قوانين الحرب البرية وأعرافها)، و(القوانين التي توفر الضمانات لأفراد القوات المسلحة غير القادرين على القتال وفئات وأعيان أخرى)، حيث إلتقيا هذين الفرعين في ما يسى اليوم (القانون الدولي الإنساني)، إذ إستعرضت المحكمة الصكوك الدولية الأولى التي نظمت هذا القانون من خلال إثارتها إلى إتفاقيات لاهاي للأعوام 1899 و1907، وإلى إعلان سان بطرسبرغ لعام 1868، وإتفاقيات جنيف للأعوام 1864 و1906 و1929 و1949، والبروتكولات الإضافية لعام 1977، حيث وصفت المحكمة تلك البروتوكولات بأنها " تعبر عن وحدة ذلك القانون وتعقيده وتثهد بذلك"، لتصل إلى إستتتاج دفاده "أن سير العمليات العسكرية تتظمه مجموعة من القواعد القانونية، ذلك لأن حق المتحاربين في إختيار وسائل وأساليب القتال ليس حقاً غير محدود". وتتاولت المحكمة تحليل المبدأين الرئيسيين الذين يحكمان القانون الدولي الإنساني، وهما مبدأ التمييز ، ومبدأ حظر التسبب بآلام لا مبرر لها. (موجز الأحكام ...، مصدر سابق، ص117). ويعد مبدأ التمييز واحداً من أهم المبادئ التي يستند اليها القانون الدولي الإنساني، حيث تم إلزام أطراف النزاع وفي جميع الأوقات بالتمييز بين الأعيان المدنية والأهداف العسكرية، ومن ثم توجيه العمليات العسكرية ضد الأهداف العسكرية دون غيرها، ولقد ظهرت بوادر مبدأ التمييز في إعلان سان بيتر سبورغ عام 1868، إذ أشار الإعلان إلى أن مبدأ التمييز بين الأعيان المدنية والأهداف العسكرية يشكل حجر الأساس في القوانين الإنسانية. (الزمالي، دون سنة نشر ، ص123) كما أن هناك مبدأ أساسية في القانون الدولي الإنساني مفاده بأن ليس (للمتحاربين حق مطلق في إختيار وسائل إلحاق الضرر بالعدو)، وعلى الرغم من أن هذا المبدأ ورد بأكثر من تعبير، إلا أن المقصود منه واضحاً، إذ نجد أنه حتى الهجمات المباشرة ضد أهداف عسكرية مشروعة تخضع لقيود قانونية، سواء بناءً على مبادئ القانون الدولي الإنساني، أو على قواعد لفروع أخر من فروع القانون الدولي، وهذا يعني أن عدم تمتع فئة معينة بالحماية بموجب أحكام القانون الدولي الإنساني، لا يعني أن الهجوم على هذه الفئة غير المحمية يكون مطلق بلا قيود. (سوادي، 2015، ص76-77) وفضلاً عن هذين المبدأين فقد أشارت المحكمة إلى شرط مارتنز ، الذي ينص على أنه "في الحالات التي لا تشملها أحكام الإتفاقية التي تم عقدها، يظل السكان المدنيون والمقاتلون تحت حماية وسلطان مبادئ قانون الأمم كما جاءت في الأعراف التي إستقر عليها الحال بين الثعوب المتمدنة وقوانين الإنسانية ومقتضيات الضمير العام"، وقد إعتبرت المحكمة إنَّ شرط مارتتز جزء من القانون الدولي العرفي، وأن شرط مارتتز "وسيلة فعالة لمعالجة التطور السريع للتقنية العسكرية". وأكدت 
المحكمة أهمية شرط مارتنز "والذي لا يمكن الثك في إستمرار وجوده وقابليته للتطبيق"، وعلى هذا الأساس أكدت المحكمة "إنَّ المبادئ الأساسية للقانون الإنساني تبقى منطبقة على جميع الأسلحة الجديدة، بما فيها الأسلحة النووية، ولا توجد دولة تجادل

$$
\text { في ذلك". (الفتوى، مصدر سابق، ص35-36). }
$$

لذا ترى المحكمة أن مبادئ القانون الدولي الإنساني حظرت في مرحلة مبكرة جداً أنواع معينة من الأسلحة، وأن هذا الحظر ناتجاً أما عن كون أن تلك الأسلحة لا تميز بين الأعيان المدنية والأعيان العسكرية، أو لا تمييز من باب أولى بين المدنيين والعسكريين، أو لما تسببه من آلام لا مبرر لها للمقاتلين، (أي أنها تحدث أضرار أكثر مما تطلبه الميزة العسكرية)، وعلى أساس ذلك تقرر المحكمة أنه "إذ كان الإستخدام المتوخى لسلاح ما لا يفي بمقتيات القانون الدولي الإنساني، فأن التهديد به يكون أيضاً مخالف لهذا القانون". (موجز الأحكام ...، مصدر سابق، ص118). ونحن نرى أن ما توصلت إليه المحكمة وهي بصدد تحليل مبادئ القانون الدولي الإنساني لا يمكن تسميته حظراً مطلقاً للسلاح النووي، فهي تحاول (كما سبق لها في أكثر من فقرة في هذه الفتوى) أن تفتي بعدم إستتناج التحريم مالم يتم دراسة كل حالة على حدة لتفحص حيثياتها، وهذا ما نراه لا يتلائم مع الطبيعة القانونية للرأي الإفتائي، الذي يختلف عن الإختصاص القضائي الذي يمكن أن يتيح للمحكمة حق تقص حيثيات كل قضية على حدة، وهذا ما نراه خلط في مفاهيم إختصاصات المحكمة.
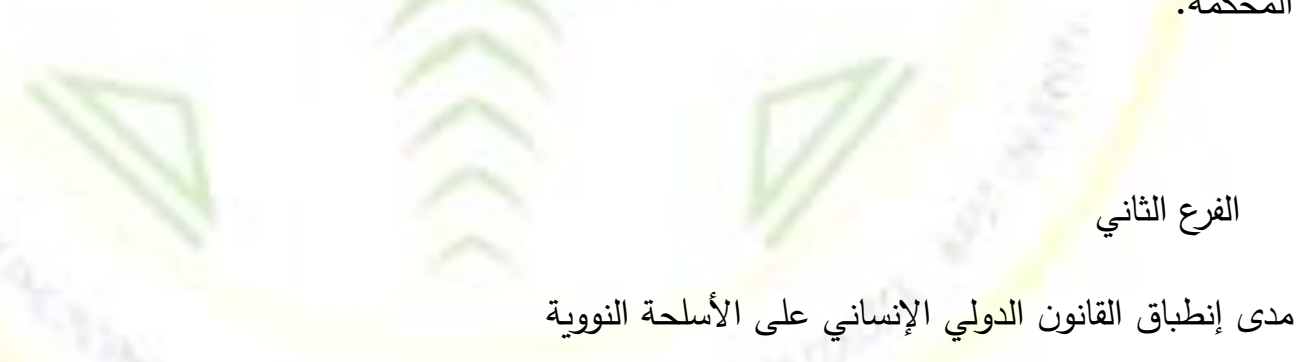

بعد إن إنتهت المحكمة من إستعراض مبادئ القانون الدولي الإنساني ذات الصلة بالقضية المعروضة، تحولت إلى الرد على الدفوع التي شككت بإنطباق أحكام القانون الدولي الإنساني على الأسلحة النووية، حيث إستشهدت المحكمة بقرار لمحكمة نورمبرغ العسكرية تقول فيه " أن قواعد القانون الدولي الإنساني الواردة في إتفاقية لاهاي لعام 1907 قد إعترفت بها جميع الأمم المتحضرة وإعتبرت مفسرة لقوانين الحرب وأعرافها". (تقارير المحكمة العسكرية الدولية، 1947، ص254). 
وترى المحكمة أن التدوين الواسع لقواعد القانون الدولي الإنساني، والإنضمام الكبير للإتفاقيات الإنسانية، وعدم إستعمال حق الإنسحاب من تلك الإتفاقيات، قد وفرت للمجتمع الدولي مجموعة من القواعد القائمة على إتفاقيات سبق للغالبية العظمى منها أن أصبحت عرفية. (موجز الأحكام ...، مصدر سابق، ص118) ودفعت الدول المؤيدة لعدم مشروعية الأسلحة النووية بأن قواعد القانون الدولي الإنساني هي قواعد آمرة على نحو ما عرفته المادة (53) من إتفاقية فينا لقانون المعاهدات لعام 1969، وترى المحكمة أن مسألة ما إذا كانت قواعد معينة تشكل أو لا تثكل قواعد آمرة، فأن ذلك يتصل بالطابع القانوني لتلك القواعد، وأن المسألة المستفتى بها من الجمعية العامة لا تثير مثل هكذا تساؤل، ولذا فأن الحكمة لا تجد أن هناك حاجة تدعوها لأن تفتي بالطبيعة القانونية لأحكام القانون الدولي الإنساني. (الفتوى، مصدر سابق، ص37). أما الدول المؤيدة لمشروعية الأسلحة النووية، فقد دفعت بأن أحكام البروتوكول الإضافي الأول لعام 1977 والمؤتمرات التي مهدت له لم تتطرق إلى قضية الأسلحة النووية، ولم تقدم أي حل لتلك المشكلة، من ثم فلا يمكن القول (حسب دفع تلك الدول) بأن أحكام البروتوكول تتطبق على القضية المعروضة، وترى المحكمة في ذلك أنه "إذا كان المؤتمر الدبلوماسي 1974-1977 لم يتتاول أسلحة معينة على وجه التحديد، فأن ذلك لا يعني جواز الخلوص إلى إستتاجات قانونية تتصل بالقضايا الموضوعية التي يثيرها إستخدام تلك الأسلحة". (موجز الأحكام ...، مصدر سابق ، ص118). كما دفعت بعض الدول (وهي قليلة حسب وصف المحكمة لها) بأن أحكام القانون الدولي الإنساني قد وجدت وإستقرت في المجتمع الدولي قبل وجود الأسلحة النووية، ومن ثم لا يمكن لقوانين سابقة تنظم أسلحة لم تكن موجودة في حينها، وأن إتفاقيات القانون الدولي الإنساني لم تتطرق إلى تلك الأسلحة على وجه التحديد، ومن ثم فلا يمكن لهذه الأحكام أن تتظم اللجوء للأسلحة النووية. (الفتوى، مصدر سابق، ص38-39). وترى المحكمة أنه من الصحيح أن الأسلحة النووية قد إخترعت بعد أن كانت معظم مبادئ القانون الدولي الإنساني وقواعده قد وجدت وإستقرت، إلا أنه لا يمكن الإستتاج أن أحكام هذا القانون ومبادئه لا تتطبق على الأسلحة النووية، فمثل هذا الإستتتاج يتتافى مع الطابع الإنساني الأصيل لذلك القانون، فالطابع الإنساني لهذا القانون يضمن له أن يحكم كافة النزاعات المسلحة، وكافة أنواع الأسلحة التي تستخدم في تلك النزاعات، وقوبل رأي المحكمة هذا بتأييد أغلبية الدول بما فيها الدول الحائزة للأسلحة النووية، فالولايات المتحدة الأمريكية وفي بيانها الخطي المقدم للمحمة بينت بأنها "تؤيد الرأي القائل أن قانون 
النزاع المسلح ينظم إستخدام الأسلحة النووية"، وكذلك الحال للممكة المتحدة التي بينت بأنها " قد قبلت دوماً أن إستخدام الأسلحة النووية خاضع للمبادئ العامة لقانون النزاع المسلح". (موجز الأحكام ...، مصدر سابق، ص118). الفرع الثالث

مدى مشروعية الأسلحة النووية في أقصى ظروف الدفاع عن النفس بعد أن إنتهت المحكمة من إستعراض مبادئ القانون الدولي الإنساني ومدى إنطباق أحكام هذا القانون على الأسلحة النووية، سنناقش في هذا الفرع القضية الأكثر تعقيداً في الفتوى، ألا وهي قضية مدى مشروعية الأسلحة النووية في أقصى ظروف الدفاع عن النفس. إدعت الدول المؤيدة لمشروعية الأسلحة النووية، أن إستخدام تلك الأسلحة ليس محظوراً في كل الظروف، فإحدى وجهات النظر ترى حقيقة اللجوء إلى الأسلحة النووية خاضعاً للقانون الدولي الإنساني، وكون أن ذلك القانون ينظم هذا اللجوء، لا يعني بالضرورة أن ذلك اللجوء بحد ذاته محظوراً، فعلا سبيل المثال حالة إستخدام سلاح نووي قليل القوة ضد سفينة حربية في أعالي البحار أو ضد جنود في منطقة خالية من السكان، فمثل هذا الإستخدام إذا كان وفقاً للآلية التي رستها المادة (51) من الميثاق، فأنه لا يمكن أن يعد غير مشروعاً وفقاً لرأي هذه الدول. (البيان الخطي للملكة المتحدة، 1996، ص40). وترى المحكمة أن الإستخدام النظيف والتكتيكي للأسلحة النووية قليلة القوة وأن كان ممكن قانوناً، إلا أنه من الممكن جداً أن يجنح إلى التصاعد إلى أن يبلغ إستخداماً كلياً للأسلحة النووية كبيرة القوة، ولما كان الأمر كذلك، فأن المحكمة ليس لديها ما يكفي من الأسس لتبت في صحة هذا الرأي، كما لا تستطيع المحكمة أن تبت في صحة الرأي القائل بأن (اللجوء للأسلحة النووية غير مشروع في أي ظرف لتعارضه مع القانون الدولي الإنساني)، إذ ترى أن ليس لديها عناصر كافية لتمكينها من أن تستخلص بدقة أن إستخدام الأسلحة النووية سيكون بالضرورة مخالفاً لمبادئ وقواعد القانون الدولي الإنساني في كل ظرف يمكن إستخدام هذا السلاح فيه بوجه عام، و في أقصى ظروف الدفاع عن النفس على وجه الخصوص. (الفتوى، مصدر سابق، ص41). لذا فأن المحكمة ترى أن ليس بإمكانها أن تغفل الحق الأساسي لكل دولة في البقاء، ومن ثم حقها في اللجوء إلى الدفاع عن النفس، وفقاً لما رسمته مادة (51) من الميثاق، عندما يتعرض بقاؤها للخطر، وليس بإمكانها تجاهل (سياسة الردع) التي تمسك بها قطاع كبير من المجتمع الدولي لفترات طويلة، لتقرر أخيراً في الثطر الثاني من( النقطة 2/ الفقرة هاء) من منطوق 
الفتوى، وبسبعة أصوات موافقة مقابل سبعة أصوات رافضة، وبصوت الرئيس المرجح أنه "بناء على ذلك، وبالنظر إلى الحالة الراهنة للقانون الدولي إذا نظر إليه بكليته على نحو ما تفحصته المحكمة أعلاه، وإلى ما تحت تصرفها من العناصر الوقائعية، فأن ثمة ما يدعو المحكمة إلى ملاحظة أنها لا تستطيع الوصول إلى إستتاج حاسم فيما يتعلق بمشروعية أو عدم مشروعية إستخدام دولة ما للأسلحة النووية في ظرف أقصى من ظروف الدفاع عن النفس، حيث يكون بقاؤها معرضاً للخطر ". (الفتوى، مصدر سابق، ص45). وفي رأيه المؤيد للفتوى والملحق بها، يقول رئيس المحكمة (محمد البجاوي): "أن الحل الذي توصلت إليه المحكمة يثبت حالة الواقع القانوني دون مجاملة، فحق الدفاع عن النفس حق مشروع إذا مورس في ظروف قصوى يكون فيها بقاء الدولة معرضاً للخطر ، ...أن توزيع الأصوات فيما يخص هذه الفقرة لم يكن قط إستجابة لأي إنقسام جغرافي، وهذا دليل على إستقلال

$$
\text { أعضاء المحكمة". (بجاوي، 1996، ص47-53). }
$$

أما القاضي (فيريشتشيتن) وفي رأيه المؤيد للفتوى والملحق بها، فقد حاول أن يفرق بين نظريتي كمال التشريع ونقصه، فمن وجهة نظره أن أصحاب الرأي الذين ينكرون فيه على المحكمة حقها بأن تعلن عدم وجود قانون يحكم الموضوع، على الرغم من عدم إنكارهم وجود ثغرات في هذا القانون، هم يدعون المحكمة أن تقوم بتأمين كمال النظام القانوني، وذلك بالإحالة إلى المبادئ القانونية العامة أو عن طريق الإنشاء القضائي للقانون، غير أن المحكمة في القضية الحالية عليها أن تصدر فتوى، وليس تسوية نزاع حقيقي بين طرفين، ولذا فأن من واجبها أن تتطق بالقانون كما هو موجود، وليس في السؤال المطروح على المحكمة أو في مرافعات الدول ما يمكن تفسيره طلب لسد ثغرات القانون، وحتى لو طلب منها ذلك كان عليها أن ترفض، لكونه لا يدخل ضمن إختصاصاتها القضائية. (فيريشتشيتن، 1996، ص58-60). أما القضاة الذي لم يصوتوا بالإيجاب لصالح هذه الفقرة وهم كل من(شويبل، أودا، شهاب الدين، ويرامانتري، كوروما، هيغينيز) فأن مفاد ما تقدموا به من آراء معارضة ملحقة بالفتوى كانت تتلخص بأن أحكام القانون الدولي ككل لا يمكن أن تكون عاجزة عن حظر الأسلحة النووية في كل ظرف، فالمبادئ العامة للقانون الدولي الإنساني وحدها كانت كفيلة بأن تحس هذا الإختلاف، وأن تردد المحكمة وعدم حسمها لهذه النقطة لا يتلائم مع مكانتها وسوابقها القضائية. أما نحن فنرى أن المحكمة لم تكن موفقة تماماً فيما توصلت إليه من نتيجة، إذ لم يكن السؤال الموجه إليها من الجمعية العامة يثير مشكلة إستخدام الأسلحة النووية في أقصى ظروف الدفاع عن النفس، لذا فأن التوسع في هذه الإثكالية لم يكن 
هناك ما ييرره، ومن جهة أخرى فأن الغموض القانوني الذي كان يكتنف مسألة مشروعية إستخدام هذه الأسلحة، كان يخدم قضية عدم المشروعية، إذ كانت إعتبارات عدم المشروعية تغلب على إعتبارات المشروعية، فالضمير الجمعي للدول والثعوب كان يميل بالفطرة إلى عدم مشروعية تلك الأسلحة، ويميل بثكل قوي إلى إدانتها وتجريمها، أما وقد تبدد هذا الغموض بقرار المحكمة أنه لا يمكنها الجزم بوضوح بمشروعية أو عدم مشروعية الأسلحة النووية في ظروف معينة، فأن ذلك سيعطي للدول الحائزة لتلك الأسلحة حق التحليل القانوني الذي مفاده أن عدم وجود قواعد تحظر السلاح النووي سيجعل منها أن تكون مباحة، لأن الأصل في الأشياء الإباحة، إلا ما كان محظوراً بموجب نص، لذا كان على المحكمة أن تحسم أمرها وتحظر تلك الأسلحة إستتاداً إلى مبدأ التمييز على أقل تقدير .

الخاتمة

بعد أن إنتهينا من البحث في (مدى مشروعية التهديد بالأسلحة النووية أو إستخدامها وفقاً للرأي الإفتائي الصادر عن محكمة العدل الدولية) سنخلص في النهاية إلى مجموعة نتائج وتوصيات نوردها على الثكل الآتي: أولاً: النتائج 1. قبلت المحكمة الإجابة على الطلب المقدم لها من الجمعية العامة، مستتدة في ذلك على إنطباق الثروط المذكورة في المادة (1/96) من ميثاق الأمم المتحدة والمادة (1/65) من نظامها الأساس، وعلى الرغم من وجاهة الحجج التي أرادت أن تثني المحكمة عن قبول الإجابة على الطلب، إلا أن المحكمة قد إستطاعت أن ترد على تلك الحجج بلغة قانونية وعملية. 2. حلت المحكمة نصوص القانون الدولي لـ (حقوق الإنسان والبيئة والحياد والتهديد بإستعمال القوة) إلا أنها في كل مرة تفتي بعدم إستتتاج التحريم ما لم يتم دراسة كل حالة ينتهك فيها واحد من هذه القوانين على حدة لتقحص حيثياتها، وهذا ما نراه لا يتلائم مع الطبيعة القانونية للرأي الإفتائي، الذي يختلف عن الإختصاص القضائي الذي يمكن أن يتيح للمحكمة حق تفحص حيثيات كل قضية بثكل مستقل ومعمق. 3. أن المحكمة إبتدعت مفهوماً جديداً ربطت من خلاله حق الدفاع عن النفس، بإستخدام السلاح النووي، وتتاست في قرارها أن حق الدفاع الثرعي مقيد بمبئي الضرورة والتتاسب، وأن الخصائص الفريدة للسلاح النووي التي أوردتها المحكمة في 
هذه الفتوى يستحيل معها أن تفي بمتطلبات هذين المبدأين، بل يستحي معها أن تفي بمتطلبات القانون الدولي الإنساني، فضلاً عن أن سؤال الجمعية العامة لم يثير أصلاً جدلية إستخدام السلاح النووي في أقصى ظروف الدفاع عن النفس. ثانياً: التوصيات

1. على الدول الحائزة للأسلحة النووية القيام بالتفاوض بحسن نية على نزع السلاح النووي وحظر تصنيعه وإستخدامه والتهديد به تحت أي ظرف كان، والإمتثال التام لمعاهدة حظر الأسلحة النووية لعام 2017 . 2. على الجمعية العامة (طالبة الفتوى)، ان تبذل المزيد من الجهود لحث الدول الحائزة للأسلحة النوية نحو الإنضمام

$$
\text { لمعاهدة حضر الأسلحة النووية لعام } 2017 .
$$

3. كما ويتوجب على محكمة العدل الدولية أن تكون أكثر حزماً ووضوحاً في آراءها الإفتائية، كما نوصيها بقراءة سريعة

لأي طلب فتوى يقدم إليها، فإذا وجدت بأن رأيها يمكن أن يكون غامضاً مثل الرأي مدار البحث، فمن الأفضل لها رد

طلب الفتوى إستتاداً إلى السطلة التقديرية الممنوحة لها، حفاظاً على مكانتها القانونية، وهيبتها القضائية.

1. سهيل حسين الفتلاوي وعماد محمد ربيع. موسوعة القانون الدولي (القانون الدولي الإنساني)، دار الثقافة للنشر والتوزيع، الأردن،

2. عامر الزمالي. الفئات المحمية بموجب أحكام القانون الدولي الإنساني، محاضرات في القانون الدولي الإنساني، منشورات اللجنة الدولية للصليب الأحمر بالقاهرة، تحرير شريف عتلم، 2007.

3. عبد علي محمد سوادي. حماية المدنيين أثناء النزاعات المسلحة، دار وائل للنشر، الأردن،2015.

4. فؤاد شباط ومحمد عزيز شكري، القضاء الدولي ، المطبعة الجديدة، دمشق، 1966.

5. كرار صالح حمودي. الحماية الدولية للأطفال والنساء في النزاعات المسلحة، منشورات زين الحقوقية، بيروت،2015. 6. نايف أحمد ضاحي الثمري. الإختصاص الإستثاري لمحكمة العدل الدولية، منشورات الحلبي الحقوقية، بيروت، 2015. 7. وليد البيطار ـ القانون الدولي العام، المؤسسة الجامعية للدراسات والنشر والتوزيع، بيروت، 2008. 
8. عربي بومدين. دراسة في العهد الدولي الخاص بالحقوق المدنية والسياسية والبرتوكول الاختياري الأول الملحق به، بحث منشور في موقع الحوار المتمدن على شبكة الأنترنيت على www.ahewar.org.

9. لويز دوسوالد- بيك. القانون الدولي الإنساني وفتاوى محكمة العدل الدولية، بحث منشور في المجلة الدولية للصليب الأحمر،

$$
\text { العدد (53) ، شباط-1997. }
$$

10. ماك كورماك. الدفع بعدم وجود قانون يحكم الأسلحة النووية، بحث منشور في المجلة الدولية للصليب الأحمر ، العدد (53) ،

$$
\text { شباط-1997. }
$$

11. مانفريد مور • بعض الأفكار المطروحة حول نقاط قوة وضعف الفتوى. محاضرة إلقيت أمام خبراء لجنة القانون الدولي الإنساني التابعة للصليب الأحمر الأماني. منشورة في مجلة اللجنة الدولية للصليب الأحمر، العدد (53)، شباط/1997.

$$
\text { ثالثاً: القرارات والتقارير والفتاوى والآراء القضائية }
$$

12.أودا. الرأي الملحق بالنص الكامل لفتوى محكمة العدل الدولية بثأن مشروعية إستخدام الأسلحة النووية أو التهديد بها،

$$
\text { 1996، منشور في الموقع الرسمي لمنظمة الأمم المتحدة على الانترنيت (www.un.org). }
$$

13.بجاوي. الرأي الملحق بالنص الكامل لفتوى محكمة العدل الدولية بثأن مشروعية إستخدام الأسلحة النووية أو التهديد بها،

$$
\text { 1996، منشور في الموقع الرسمي لمنظمة الأمم المتحدة على الانترنيت (www.un.org). }
$$

14. البيانات الخطية المقدمة من الولايات المتحدة الأمريكية والمملكة المتحدة وفرنسا فلندا وهولندا و المانيا. مشار لها بالنص الكامل لفتوى محكمة العدل الدولية بشأن مشروعية إستخدام الأسلحة النووية أو التهديد بها،1996، منشورة في الموقع الرسمي

$$
\text { لمنظمة الأمم المتحدة على الانترنيت (www.un.org). }
$$

15.تفسير إتفاق 25/آذار/1951 بين منظمة الصحة العالمية ومصر ،1951.

16.تقارير المحكمة العسكرية الدولية. محاكمة مجرمي الحرب الرئيسيين، نورمبرغ،947 ، المجلد 1. 
17.شويبل. الرأي الملحق بالنص الكامل لفتوى محكمة العدل الدولية بشأن مشروعية إستخدام الأسلحة النووية أو التهديد بها، 1996، منشور في الموقع الرسمي لمنظمة الأمم المتحدة على الانترنيت (www.un.org). 18.شي جيويونغ. الرأي الملحق بالنص الكامل لفتوى محكمة العدل الدولية بشأن مشروعية إستخدام الأسلحة النووية أو التهديد بها،1996، منشور في الموقع الرسمي لمنظمة الأمم المتحدة على الانترنيت (www.un.org). 19.غيوم. الرأي الملحق بالنص الكامل لفتوى محكمة العدل الدولية بثأن مشروعية إستخدام الأسلحة النووية أو التهديد بها،1996، منشور في الموقع الرسمي لمنظمة الأمم المتحدة على الانترنيت (www.un.org). 20. الفتوى. النص الكامل لفتوى محكمة العدل الدولية بثأن مشروعية إستخدام الأسلحة النووية أو التهديد بها والصادرة عام 1996، منشورة في الموقع الرسمي لمنظمة الأمم المتحدة على الانترنيت (www.un.org). 21.فيريتشيتن. الرأي الملحق بالنص الكامل لفتوى محكمة العدل الدولية بثأن مشروعية إستخدام الأسلحة النووية أو التهديد بها، 1996، منشور في الموقع الرسمي لمنظمة الأمم المتحدة على الانترنيت (www.un.org). 22.قرار الجمعية العامة للأمم المتحدة، رمز الوثيقة (A/49/75)، منشور في الموقع الرسمي لمنظمة الأمم المتحدة على الانترنيت (www.un.org).

23. قضية الأنشطة العسكرية وشبه العسكرية في نيكاراغوا وضدها( نيكاراغوا ضد الولايات المتحدة الأمريكية)، مشار لها في تقارير محكمة العدل الدولية، تقرير عام 1986. 24.قضية الرصيف القاري بين الجماهيرية العربية الليبية ودولة مالطة. مشار لها في تقارير محكمة العدل الدولية، تقرير عام .1985 25.موجز الأحكام والفتاوى والأوامر الصادرة عن محكمة العدل الدولية 1992-1996، منشورات الأمم المتحدة، نيويورك، 1998، منشورة في الموقع الرسمي لمنظمة الأمم المتحدة على الانترنيت (www.un.org). 26.ميثاق الأمم المتحدة، 1945، منشور في الموقع الرسمي لمنظمة الأمم المتحدة على الانترنيت (www.un.org). 27.ويرمانتري. الرأي الملحق بالنص الكامل لفتوى محكمة العدل الدولية بثأن مشروعية إستخدام الأسلحة النووية أو التهديد بها،1996، منشور في الموقع الرسمي لمنظمة الأمم المتحدة على الانترنيت (www.un.org). 
مجلة لارك لدفلسفة و الذسداذيات و العلوم الاجتماعية المجلد (4) العدد (43) السذة (2021) بحوث الدقاذون والدلوم السياسدية

ثالثاً: المصادر الإنكليزية

28. Alexandre Charles Kiss, Dinah Shelton, International Environmental Law, Transnational

Publishers, 1991.

29. Kelsen. H., The Law Of The United Nations, The Library Of World Affairs, New York, 1951.

30. Gowlland- D.V., The relationship Between The I.C.J.And The Security Council In The Light of The Lockerbie Case,A.J.I.L.,vol.88, No. 4, 1994. 